\title{
Downregulation of Sphingosine 1-Phosphate Receptor 1 Promotes the Switch from Tangential to Radial Migration in the $\mathrm{OB}$
}

\author{
- Julieta Alfonso, ${ }^{*}$ - Horst Penkert, ${ }^{\star}$ Ceren Duman, Annalisa Zuccotti, and Hannah Monyer \\ Department of Clinical Neurobiology at the University Hospital Heidelberg and German Cancer Research Center, 69120 Heidelberg, Germany
}

Neuroblast migration is a highly orchestrated process that ensures the proper integration of newborn neurons into complex neuronal circuits. In the postnatal rodent brain, neuroblasts migrate long distances from the subependymal zone of the lateral ventricles to the olfactory bulb (OB) within the rostral migratory stream (RMS). They first migrate tangentially in close contact to each other and later radially as single cells until they reach their final destination in the $\mathrm{OB}$. Sphingosine 1-phosphate (S1P) is a bioactive lipid that interacts with cell-surface receptors to exert different cellular responses. Although well studied in other systems and a target for the treatment of multiple sclerosis, little is known about S1P in the postnatal brain. Here, we report that the S1P receptor 1 (S1P1) is expressed in neuroblasts migrating in the RMS. Using in vivo and in vitro gain- and loss-of-function approaches in both wild-type and transgenic mice, we found that the activation of S1P1 by its natural ligand S1P, acting as a paracrine signal, contributes to maintain neuroblasts attached to each other while they migrate in chains within the RMS. Once in the OB, neuroblasts cease to express S1P1, which results in cell detachment and initiation of radial migration, likely via downregulation of NCAM1 and $\beta 1$ integrin. Our results reveal a novel physiological function for S1P1 in the postnatal brain, directing the path followed by newborn neurons in the neurogenic niche.

Key words: cell adhesion; migration; olfactory bulb; retrovirus; sphingosine; time lapse

\section{Significance Statement}

The function of each neuron is highly determined by the position it occupies within a neuronal circuit. Frequently, newborn neurons must travel long distances from their birthplace to their predetermined final location and, to do so, they use different modes of migration. In this study, we identify the sphingosine 1-phosphate (S1P) receptor 1 (S1P1) as one of the key players that govern the switch from tangential to radial migration of postnatally generated neuroblasts in the olfactory bulb. Of interest is the evidence that the ligand, S1P, is provided by nearby astrocytes. Finally, we also propose adhesion molecules that act downstream of S1P1 and initiate the transition from tangential chain migration to individual radial migration outside of the stream.

\section{Introduction}

The formation of complex cerebral circuits relies on the integration of newborn neurons that often reach their remote site of destination following stereotyped migratory routes. Both during development and in the postnatal brain, neuroblasts use different migratory

\footnotetext{
Received April 9, 2015; revised Aug. 28, 2015; accepted Aug. 29, 2015

Author contributions: J.A., H.P., A.Z., and H.M. designed research; J.A., H.P., and C.D. performed research; J.A., H.P., C.D., A.Z., and H.M. analyzed data; J.A. and H.M. wrote the paper.

This work was supported by the German Federal Ministry for Education and Research (Grant BMBF 01GQ1405 to J.A., H.P., C.D., and A.Z.). We thank J. Friemann and R. Hinz-Herkommer for excellent technical assistance and R. Proia (National Institutes of Health) for kindly providing the anti-SK2 antibody.

The authors declare no competing financial interests.

*J.A. and H.P. contributed equally to this work.

Correspondence should be addressed to either Julieta Alfonso or Hannah Monyer, Im Neuenheimer Feld 280, DKFZ A230, 69120 Heidelberg, Germany. E-mail: j.alfonso@dkfz-heidelberg.de or h.monyer@dkfz-heidelberg.de. DOI:10.1523/JNEUROSCI.1353-15.2015

Copyright $\odot 2015$ the authors $\quad 0270-6474 / 15 / 3513659-14 \$ 15.00 / 0$
}

modes to arrive at the precise position where they differentiate and mature. In the subependymal zone (SEZ), the largest neurogenic niche of the postnatal rodent brain, thousands of neurons are born every day throughout life (Ihrie and Alvarez-Buylla, 2011). These young neurons travel several millimeters along the rostral migratory stream (RMS) toward the olfactory bulb (OB), engaging in a particular form of tangential migration known as chain migration that involves close contact of the neuroblasts with each other (Lois and Alvarez-Buylla, 1994; Wichterle et al., 1997). Once in the OB, individual cells disperse and migrate radially to reach the proper layer of the $\mathrm{OB}$, where they differentiate into specific types of neurons (mainly interneurons: granule and periglomerular cells) and integrate into already established olfactory circuits (Carleton et al., 2003). The new neurons eventually take part in complex cognitive functions such as perceptual learning and olfactory memory (Lazarini and Lledo, 2011). 
The identification of factors governing neuroblast migration provides insight into basic mechanisms governing neurogenesis and thus holds therapeutic potential when considering repair strategies that involve redirecting newborn neurons to specific brain areas after injury. Several molecules involved in tangential migration in the RMS have been identified so far. Among them, several adhesion molecules, cytoskeletal regulators, axon guidance molecules, neurotransmitters, and growth factors are known to be important in this process (for review, see Lalli, 2014). However, little is known about the cellular and molecular mechanisms underlying the switch from tangential to radial migration, not only in the postnatal brain, but also during embryonic development. Three extracellular matrix molecules have been related to this process in the OB: Reelin, Tenascin-R, and Prokineticin 2 (Hack et al., 2002; Saghatelyan et al., 2004; Ng et al., 2005). Nevertheless, we are still far from understanding the cellular mechanisms that mediate the transition between the two modes of migration.

Sphingosine 1-phosphate (S1P) is a bioactive lipid synthesized by the sphingosine kinase (SK) isoenzymes SK1 and SK2 and secreted into the extracellular milieu, where it signals via G-protein-coupled receptors (S1P1-5; Maceyka et al., 2012). The S1P receptors are distributed differentially throughout various tissues, where they mediate a variety of cellular processes including cell proliferation, survival, migration, angiogenesis, and differentiation (O'Sullivan and Dev, 2013). The S1P axis is particularly well studied in the immune and vascular systems and has been implicated in a broad range of diseases including cancer and inflammatory disorders (Kunkel et al., 2013). In fact, S1P1 is a known drug target for multiple sclerosis (Brinkmann et al., 2010). In contrast to the extensive information regarding the function of S1P1 in other systems, little is known about the role of S1P1 in the brain, although it is known to be highly expressed in the CNS (Liu and Hla, 1997; Chae et al., 2004).

Here, we investigated the role of S1P1 during postnatal neurogenesis in the SEZ/RMS/OB system. We performed in vivo and in vitro gain- and loss-of-function experiments and identified a novel physiological function for S1P1 in directing the switch from tangential to radial migration. Moreover, our results revealed a molecular mechanism by which neuroblasts in the $\mathrm{OB}$ are released from chain aggregates and undergo single-cell radial migration via downregulation of cell adhesion molecules.

\section{Materials and Methods}

Animals. We used wild-type C57BL/6 mice (Charles River Laboratories) and the transgenic S1P1 loxP/loxP MashCRE ${ }^{\mathrm{ERT} 2}$ mice of either sex resulting from the cross of $\mathrm{S} 1 \mathrm{P} 1^{\text {loxP/loxP }}$ and MashCRE ${ }^{\mathrm{ERT} 2}$ mice (http:// jaxmice.jax.org/strain/019141.html and http://jaxmice.jax.org/strain/ 012882.html; The Jackson Laboratory). Tamoxifen was dissolved in ethanol $(40 \mathrm{mg} / \mathrm{ml})$, diluted $1 / 20$ in corn oil (Sigma-Aldrich) and injected intraperitoneally $100 \mu \mathrm{g}$ twice per day for 5 consecutive days from postnatal day 7 (P7) to P11. Animal care and procedures were according to local and international regulations for the use of experimental animals.

Immunostainings. Mice were perfused with $4 \%$ paraformaldehyde in PBS and the brains were postfixed overnight. Then, $50-70 \mu \mathrm{m}$ sections were cut on a vibratome (Leica VT 1000S). Free-floating sections were permeabilized and blocked in $0.2 \%$ Triton, 3\% BSA-PBS for at least 30 min and incubated overnight at $4^{\circ} \mathrm{C}$ with the primary antibody (in $3 \%$ BSA-PBS). After 3-4 washes in PBS, sections were incubated with the secondary antibody (in 3\% BSA-PBS) for 1-2 h, washed again, and mounted. For BrdU stainings, an additional treatment of $1 \mathrm{M} \mathrm{HCl}$ at $45^{\circ} \mathrm{C}$ for $45 \mathrm{~min}$, followed by $15 \mathrm{~min}$ in Tris- $\mathrm{HCl} 10 \mathrm{~mm}, \mathrm{pH}$ 8, was performed before permeabilization and blocking. Primary antibodies were as follows: rabbit anti-S1P1/EDG1 (1:300; Abcam), goat anti-DCX (1:500; Santa Cruz Biotechnology), mouse anti-BrdU (1:1000; BD PharMin- gen), rabbit anti-active caspase-3 (1:1500; BD PharMingen), mouse antiGFAP (1:1000; Sigma-Aldrich), chicken anti-GFP (1:1000; Abcam), rabbit anti-DsRed (1:1000; Clontech), mouse anti-Tuj1/TubulinIII (1: 1000; Sigma-Aldrich), mouse anti-PSA-NCAM (1:1000; e-Biosciences), rabbit anti-SK1 (1:1000; Abcam), rabbit anti-SK2 (kindly provided by Prof. Richard Proia, National Institutes of Health). Secondary antibodies were as follows: anti-chicken, anti-goat, and anti-mouse conjugated to Alexa Fluor 488 and anti-mouse and anti-rabbit conjugated to Alexa Fluor 647 (all from Invitrogen) and anti-rabbit Cy3 (Jackson ImmunoResearch).

Plasmid constructs and Western blots. The following shRNA target sequences were cloned into the pSUPER.basic RNAi vector (OligoEngine) downstream of the $\mathrm{H} 1$ promoter: scrambled sequence: CTACCGTTGTTATAGGTG, shRNA S1P1a: CTCTACCACAAGCACTATATT, shRNA S1P1b: TCATCCCAGGCATGGAATTTA, shRNA SK2: TGTCCCTCTC CCTAGTCTAAA. shRNA SK1 (target sequence GGGTACGAGCAGGTGACTAAT) was cloned into pGFP-V-RS-shRNA vector (OriGene) downstream of the U6 promoter. For retrovirus constructs, shRNA sequences together with the $\mathrm{H} 1$ promoter were subcloned into a murine Moloney leukemia virus (MMLV)-based retroviral vector expressing either palmitoylated EGFP or RFP under the control of the RSV promoter. For AAV constructs, shRNA SK1 sequence with the U6 promoter and shRNA SK2 sequence with the H1 promoter were subcloned into the AAV backbone containing the Tomato sequence driven by the CAG promoter. The coding sequence of S1P1 was amplified by PCR from a mouse cDNA brain library. For in vivo experiments, S1P1-CDS lacking the stop codon was cloned in frame into the MMLV backbone, resulting in an RSV-S1P1-T2A-Tomato sequence. For in vitro experiments, S1P1CDS was inserted between the promoter and the IRES sequence of an AAV backbone encoding CAG-IRES-Tomato.

To test S1P1 shRNA efficiency, HEK 293 cells were cotransfected with a plasmid expressing S1P1 and a pSUPER plasmid with shRNA scrambled, shRNA S1P1a, or shRNA S1P1b. To test SK2 shRNA efficiency, HEK 293 cells were cotransfected with a plasmid expressing SK2 (CDS+UTR)-IRES-Tomato and a plasmid expressing shRNA scrambled, shRNA SK1, shRNA SK2, or shRNA SK2 plus shRNA SK1. Given that both the shRNA target sequence (SK2) and the Tomato sequence are part of the same transcript, we analyzed the expression levels for Tomato to evaluate shRNA SK2 silencing. Three days after transfection, the cells were resuspended in lysis buffer containing the following: $10 \mathrm{~mm}$ Tris$\mathrm{HCl} \mathrm{pH}$ 7.6, $150 \mathrm{~mm} \mathrm{NaCl}, 1 \%$ Triton $\mathrm{X}-100,0.1 \%$ SDS, and $1 \times$ protease inhibitor mixture complete EDTA-free (Roche) and stored at $-20^{\circ} \mathrm{C}$. Approximately $10 \mu \mathrm{g}$ of total protein extracts were separated by SDSPAGE, transferred onto nitrocellulose membranes, and blocked in $10 \%$ milk-PBS-T for $1 \mathrm{~h}$ at room temperature (RT). First antibody incubation was in PBS-T for $2 \mathrm{~h}$ at RT, followed by 3 washes in PBS-T and secondary antibody incubation for $45 \mathrm{~min}$ at RT. S1P1 and Tomato proteins were detected with rabbit anti-EDG1/S1P1 (1:1000; Abcam) or monoclonal anti-DsRed antibodies (1:1000; Clontech), respectively. As a loading control, the housekeeping genes Dynein (anti-Dynein monoclonal antibody 1:2000; Millipore) and $\beta$-actin (rabbit anti- $\beta$-actin 1:40000; Sigma-Aldrich) were used. Secondary antibodies were anti-mouse and anti-rabbit peroxidase-conjugated (1:40000; Vector Laboratories). The ECL+ Western Blot Detection System (GE Healthcare) was the chemiluminescent substrate and blots were developed with Hyperfilm-ECL (GE Healthcare).

Viral production and injections. Retrovirus production was performed as described previously (Laplagne et al., 2006). Briefly, HEK 293 cells were cotransfected with the viral backbone vector, the Gag-Pol precursor protein plasmid, and the vesicular stomatitis virus glycoprotein plasmid. Viral particles were harvested, concentrated, and purified $2 \mathrm{~d}$ later by repetitive ultracentrifugation. The concentrated viral solutions $\left(10^{6}-10^{8}\right.$ $\mathrm{cfu} / \mathrm{ml}$ ) were titrated and stored at $-80^{\circ} \mathrm{C}$. $\mathrm{P} 4-\mathrm{P} 6$ pups were anesthetized with isoflurane and stereotactically injected into the SEZ (coordinates from bregma: $0,5 \mathrm{~mm}$ anterior; $1 \mathrm{~mm}$ lateral; $1,5 \mathrm{~mm}$ ventral) with $1 \mu \mathrm{l}$ of the viral solution through a glass micropipette. Pups were returned to their mother and either decapitated or anesthetized and perfused 3-15 d after virus injection. For injections in adult animals, 9-week-old mice were anesthetized with isoflurane and stereotactically 
injected into the SEZ (coordinates from bregma: $0.9 \mathrm{~mm}$ anterior; 1.2 $\mathrm{mm}$ lateral; $2.5 \mathrm{~mm}$ ventral) with $1.5 \mu \mathrm{l}$ of the viral solution through a glass micropipette. The animals were placed on a heating pad and returned to their home cages. For proliferation studies, animals received two intraperitoneal BrdU pulses of $30 \mathrm{mg} / \mathrm{kg}$ body weight at an interval of $6 \mathrm{~h}$ on day 3 after intracranial virus injection.

AAVs were produced in the packaging cell line HEK 293 using the viral backbone and the helper plasmids pDP1 and pDP2. Transfected cells were scraped from plates, transferred to a $15 \mathrm{ml}$ tube, and centrifuged at $800 \mathrm{rpm}$ for $10 \mathrm{~min}$. The pellets were lysed in $1 \mathrm{ml}$ of Tris- $\mathrm{NaCl}(20 \mathrm{~mm}$ Tris, $\mathrm{pH} 8,150 \mathrm{~mm} \mathrm{NaCL}$ ) and frozen at $-20^{\circ} \mathrm{C}$. After thawing, benzonase endonuclease was added $(50 \mathrm{U} / \mathrm{ml})$, incubated at $37^{\circ} \mathrm{C}$ for $1 \mathrm{~h}$, and the solution was centrifuged to discard cell debris. The supernatant was transferred to a fresh tube, filtered through a $0,45 \mu \mathrm{m}$ Acrodisc filter, and stored at $-80^{\circ} \mathrm{C}$ until usage.

Time-lapse videos. Retrovirally injected mice were killed by decapitation 5-9 d postinjection (d.p.i.). Brains were removed and placed in ice-cold ACSF. Then, $250-\mu \mathrm{m}$-thick parasagittal brain sections were prepared using a vibratome (HR2; Sigmann Elektronik) and kept submerged in ACSF at $32^{\circ} \mathrm{C}$. Sections were subsequently transferred to the recording chamber and continuously superfused with ACSF at $32^{\circ} \mathrm{C}$. Imaging was performed on a TCS SP 5 microscope (Leica) equipped with a $10 \times[0.3$ numerical aperture (NA)] water-immersion objective for the OB and a $20 \times(1 \mathrm{NA})$ water-immersion objective for the RMS. Videos were made from 3D stacks acquired sequentially every 13 min for up to $12 \mathrm{~h}$ for the OB and every $5 \mathrm{~min}$ for up to $5 \mathrm{~h}$ for the RMS. Summation projections were subsequently aligned in ImageJ software and the MTrackJ Plugin was used to track neuroblasts. Only neuroblasts tracked for $>9$ frames were used to calculate the distance covered over time.

Explant cultures. Brains from P6-P10 mice were removed in cold PBSglucose and sliced into $\sim 400-\mu \mathrm{m}$-thick coronal sections. We used the sections containing the lateral ventricle to dissect the SEZ and the tissue was minced into $\sim 200-400 \mu \mathrm{m}$ pieces before plating. For the pharmacological experiments, the explants were plated on top of an astrocyte monolayer prepared from cortical tissue of P5-P7 mice. Briefly, brains were removed as described above, the cortex was dissected, minced into small pieces and placed on ice. The tissue was incubated with papain $(0.08 \%) / D N a s e ~ I ~(0.001 \%)$ for $3 \mathrm{~min}$ at $37^{\circ} \mathrm{C}$ to obtain single-cell suspensions that were then plated at a density of 100,000 cells/ml in DMEM (Invitrogen) supplemented with 10\% FBS and penicillin/streptomycin. Primary astrocyte cultures were grown for at least $7 \mathrm{~d}$ and, before plating the SEZ explants, the medium was changed to B27 serum-free neurobasal medium (Invitrogen). Four to $6 \mathrm{~h}$ after plating the SEZ explants, W146 (Sigma-Aldrich) dissolved in methanol $1 \mathrm{~mm}$ and diluted in medium to a final concentration of $1 \mu \mathrm{M}$, CYM 5442 (Sigma-Aldrich) dissolved in DMSO $5 \mathrm{~mm}$ and diluted in medium to a final concentration of $0.5 \mu \mathrm{M}$, or control medium (only methanol or DMSO at the same final concentration as with the drugs) were added. For the viral infections, SEZ explants were incubated with AAVs (expressing either only Tomato or also S1P1) for $15 \mathrm{~min}$ at RT and grafted into Matrigel Basement Membrane Matrix (BD Biosciences) diluted 1:3 in B27 serum-free neurobasal medium (Invitrogen). After 2-4 d, explants were fixed in 4\% PFA-PBS and immunostained. For quantification, the percentage of single and attached neuroblasts was counted with ImageJ software.

Real-time PCR. The brains from tamoxifen-treated mice were removed in cold PBS, the OBs were isolated, and the rest of the brain sliced into $\sim 400-\mu \mathrm{m}$-thick sagittal sections. The anterior RMS (from the elbow to the beginning of the $\mathrm{OB}$ ) was dissected under a stereomicroscope (Stemi CV6; Zeiss). The tissue was immediately frozen in dry ice and kept at $-80^{\circ} \mathrm{C}$ until use. Total RNA was purified using Master Pure RNA Purification kit (Epicenter) and the cDNA was synthetized with High Capacity cDNA Reverse Transcription kit (Applied Biosystems). Quantitative real-time PCRs were performed with KiCqstart SYBRGreen qPCR ReadyMix (Sigma-Aldrich). Primer sequences were as follows: S1P1 CGCAGTTCTGAGAAGTCTCTGG forward and GGATGTCA CAGGTCTTCGCCTT reverse, DCX CTGACTCAGGTAACGACCAAGAC forward and TTCCAGGGCTTGTGGGTGTAGA reverse, Cyclophilin AAGCATACAGGTCCTGGCATCT forward and CATTCAGTCT TGGCAGTGCAG reverse, NCAM1 GCAGTTTACAATGCTGCGAA forward and TCCAACGCTGATTTCTCCTT reverse, Itgb1 ACACCGACCCGAGACCCT forward and CAGGAAACCAGTTGCAAATTC reverse, VCAM CCGGCATATACGAGTGTGAA forward and TAGAG TGCAAGGAGTTCGGG reverse, Cadherin12 TTGATCACCGAGAGTATTTCAA forward and GGTTTAGTGCAGGGACAGGA reverse, Catenin betal GAGCCGTCAGTGCAGGAG forward and CAGCTTGAG-

TAGCCATTGTCC reverse. Each sample was measured in triplicate.

Statistical analysis. Statistical analysis was calculated with Prism software (GraphPad Software). Datasets were first tested for Gaussian distribution (Kolmogorov-Smirnov test). Samples that passed the normality test were analyzed with a $t$ test (unpaired, two-tailed) or one-way ANOVA followed by Bonferroni post test. Samples that did not show normal distribution were analyzed with nonparametric tests (MannWhitney, two-tailed). Graphs in the figures show mean + SEM.

\section{Results}

\section{S1P1 loss and gain of function in postnatally born neuroblasts affects their spatial distribution along the $\mathrm{RMS} / \mathrm{OB}$}

The presence of S1P1 in the postnatal brain has been reported previously for neurons, astrocytes, Bergmann glia, and oligodendrocytes (Rao et al., 2003; Yu et al., 2004; Choi et al., 2011; Gonzalez-Cabrera et al., 2012). In situ hybridization data show a prominent expression of S1P1 in the RMS at different ages (Fig. 1A) and immunohistochemistry experiments revealed that mainly neuroblasts (labeled with doublecortin) migrating tangentially along the RMS were positive for S1P1 (Fig. $1 B, C$ ). Inside the $\mathrm{OB}, \mathrm{S} 1 \mathrm{P} 1$ expression declined in radially migrating neuroblasts that had detached from the $\mathrm{RMS}^{\mathrm{OB}}$ (Fig. 1C,D). This observation suggested a role for S1P1 during neurogenesis, so we investigated a putative function of this receptor in the postnatal neurogenic niche.

To study the role of S1P1 in vivo in the RMS, we knocked down the receptor specifically in newborn neuroblasts by injecting genetically modified retroviruses into the SEZ of P4-P5 pups, an age when OB neurogenesis is at its peak (Hinds, 1968; Bayer, 1983). Mice were infected with a mixture of a control virus expressing a scrambled shRNA sequence plus a red fluorescent protein and a knock-down virus expressing shRNA against S1P1 plus a green fluorescent protein (Fig. $2 A-C$ ). This way, we could analyze the behavior of control and mutant neuroblasts in vivo in the same brain slices, thus preventing the variability that might result from technical manipulations and/or interindividual differences. At 6 d.p.i., we analyzed the location of the infected cells in the $\mathrm{OB}$ and classified the neuroblasts into two groups: cells migrating within the RMS ${ }^{\mathrm{OB}}$ and cells outside the RMS ${ }^{\mathrm{OB}}$ closer to the outer layers of the OB (Fig. 2D). Compared with control cells, S1P1 knock-down cells were more frequently beyond the border of the RMS ${ }^{\mathrm{OB}}$ (Fig. 2E). Similar results were found when the effect of S1P1 knock-down was tested in adult mice ( 9 weeks old): S1P1 KD cells/control cells: $1 \pm 0.06$ within $\mathrm{RMS}^{\mathrm{OB}}, 2.08 \pm 0.22$ outside RMS $^{\mathrm{OB}}$ ( $n=7$ mice, 440 and 2179 control and S1P1 KD cells, respectively, $t$ test $p=0.0005)$. In a more detailed analysis, we subdivided the cells outside the RMS ${ }^{\mathrm{OB}}$ according to their rostro-caudal position in the $\mathrm{OB}$, and found that the effect of S1P1 knock-down was comparable in the rostral and caudal OB: S1P1 KD cells/control cells: $2.28 \pm 0.24$ outside RMS ${ }^{\mathrm{OB}}$ rostral and $2.6 \pm 0.32$ outside RMS ${ }^{\mathrm{OB}}$ caudal $(n=6$ mice, 191 and 1710 control and S1P1 KD cells, respectively, $t$ test $p=0.63$ ).

During the first postnatal weeks, a fraction of newborn neurons leave the RMS before reaching the $\mathrm{OB}$ and migrate radially toward the cortex to populate the deeper cortical layers (Inta et al., 2008; Le Magueresse et al., 2011). We also investigated whether this radial migration was affected by S1P1 by analyzing 
A
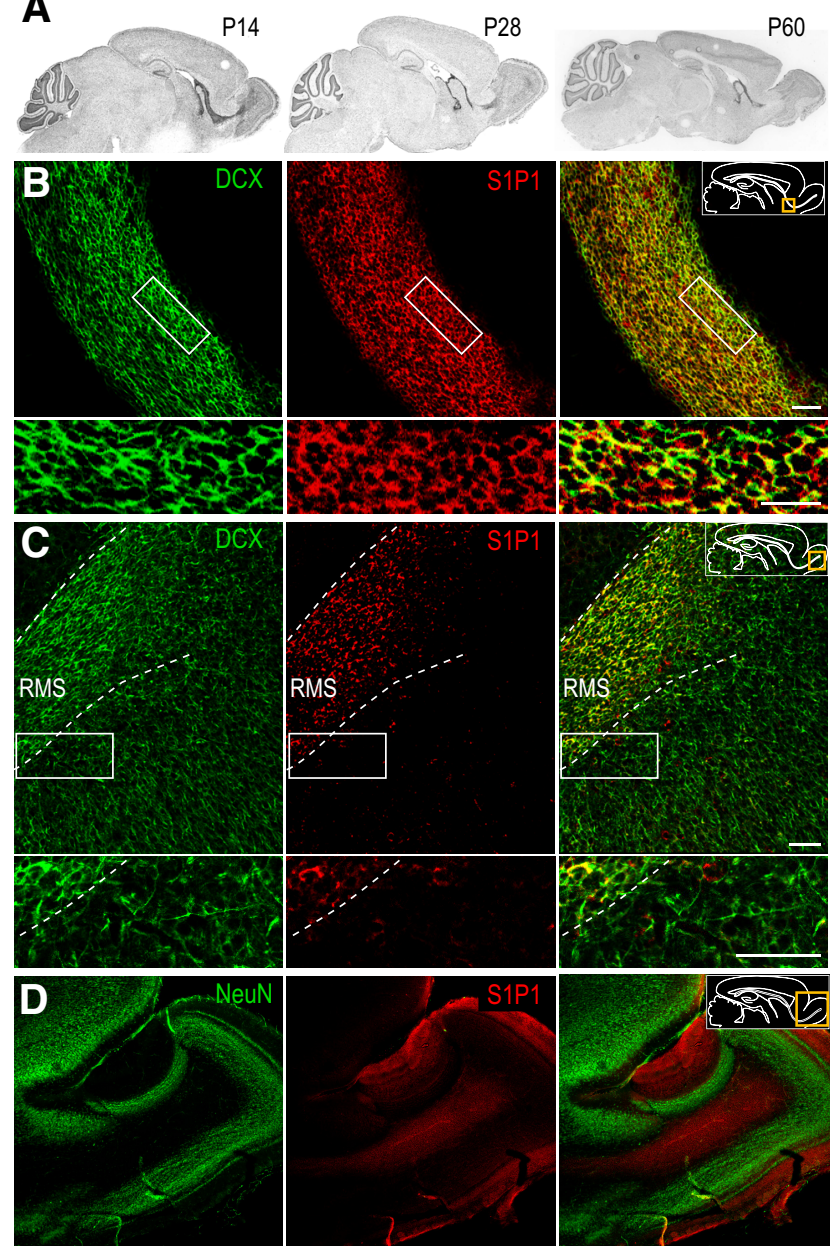

Figure 1. S1P1 is expressed in RMS neuroblasts. $\boldsymbol{A}$, In situ hybridization of S1P1 in sagittal mouse brain sections at the indicated ages showing strong expression of the receptor in the RMS (images obtained from the Allen Brain Atlas). $\boldsymbol{B}, \boldsymbol{C}$, Double immunostainings showing S1P1 expression (red) in DCX-positive neuroblasts (green) along the RMS before entering the $O B(B)$ and inside the $O B(C)$. The rectangles delineate the region depicted at a higher magnification below. $D$, Overview of the $O B$ costained with the mature neuronal marker NeuN (green) and S1P1 (red). The insets in the upper corner indicate the brain area shown in the picture. Note the decline in S1P1 expression in radially migrating neuroblasts inside the $0 \mathrm{~B}$. Scale bars, $50 \mu \mathrm{m}$.

the neuroblasts migrating in the posterior RMS close to the SVZ (Fig. $2 F$ ). We quantified the number of infected cells migrating radially in the corpus callosum in young pups, and found that more S1P1 knock-down cells had exited the RMS compared with controls (Fig. 2G). However, we did not find neuroblasts detaching from the RMS in areas where radial migration does not occur under physiological conditions, nor a difference in the orientation of neuroblasts migrating within the RMS (control $=88.01 \pm$ $1.46, \mathrm{~S} 1 \mathrm{P} 1 \mathrm{KD}=87.64 \pm 1.48 \%$ cells with a leading process directed toward the OB, $n=7$ mice, 453 and 971 control and S1P1 KD cells, respectively. $t$ test $p=0.69$ ). These results suggest that S1P1 likely acts in concert with other signaling pathways active at the time and in the brain areas where the switch from tangential to radial migration normally takes place.

As a complementary approach, we performed in vivo experiments overexpressing the receptor. Young mice were injected in the SVZ with a mixture of control retrovirus expressing only EGFP and an overexpressing virus encoding the S1P1 CDS in frame with the Tomato sequence (Fig. $2 H, I$ ). Six days later we analyzed the spatial distribution of control and mutant neuro- blasts in the OB (Fig. 2J). Quantification of fluorescent cells within and outside the RMS ${ }^{\mathrm{OB}}$ showed that a higher proportion of S1P1-overexpressing neuroblasts remained within the RMS ${ }^{\mathrm{OB}}$ compared with control cells (Fig. $2 \mathrm{~K}$ ). Therefore, in vivo loss and gain of function of S1P1 produce opposite effects in migrating neuroblasts in the $\mathrm{OB}$.

\section{Neuroblasts lacking S1P1 maintain normal levels of proliferation and survival}

Next, we evaluated whether S1P1 knock-down alters the rate of proliferation, and hence labeled the retrovirally infected neuronal progenitors (either with knock-down or control virus) with the thymidine analog BrdU, as depicted in Figure $3 A$. We then quantified the amount of BrdU-positive cells in each viral population and the results showed no difference between groups (Fig. $3 B, C)$, suggesting that S1P1 does not play a role in postnatal neuroblast proliferation. In addition, the percentage of fast dividing progenitors positive for Mash1 was equal between groups (data not shown). We next investigated whether the lack of S1P1 might affect the survival of migrating neuroblasts by staining the infected cells with the apoptotic marker Active Caspase- 3 at 3 d.p.i. and 6 d.p.i (Fig. 3D). The results showed a low proportion of apoptotic cells in both control and knock-down cells, with comparable levels between the two experimental groups (Fig. $3 E, F)$. Therefore, the observed changes in spatial distribution cannot be explained by a difference in survival.

\section{S1P1 downregulation favors the transition from tangential to radial migration}

We subsequently evaluated the migratory behavior of S1P1knock-down cells in their natural environment by time-lapse imaging in acute slices from the RMS/OB. Mice were injected with a viral mixture of control and S1P1 knock-down retroviruses and killed 5-9 d.p.i. to obtain $\mathrm{OB}$ sagittal sections containing the $\mathrm{RMS}^{\mathrm{OB}}$ (Fig. 4A). The sections were monitored over several hours to follow the trajectory of migrating neuroblasts labeled with the different retroviruses. The migratory pattern of cells was classified as tangential (along the RMS ${ }^{\mathrm{OB}}$ ), detaching (cells that first migrate tangentially and then radially), or radial (cells migrating outside the RMS ${ }^{\mathrm{OB}}$ toward the granule cell layer; Fig. $4 B$ ). As described previously (Nam et al., 2007; Snapyan et al., 2009; David et al., 2013), neuroblasts migrate in a saltatory way combining periods of active displacement with stationary phases. We tracked the cells over time (see example in Fig. $4 C$ ) and measured the distance covered per hour (a parameter that includes the speed and time spent in a stationary phase; Fig. $4 D$ ). In general, the distance traveled per hour decreased when neuroblasts switched to radial migration, which is consistent with previous data (David et al., 2013). There was no difference in the distance covered per hour between control and S1P1-knock-down infected cells (Fig. 4D). Similarly, the net distance traveled by neuroblasts, the resulting distance from the starting to the final point, was not changed between experimental groups (data not shown). Notably, when we classified cells according to their migration pattern, we found that a higher proportion of S1P1 knock-down cells engaged in radial migration compared with control cells (we grouped detaching and radial cells into radially migrating cells; Fig. $4 E$ ). These results indicate that S1P1 negatively modulates the initiation of radial migration and explains the increased number of knock-down cells observed in more superficial layers of the $\mathrm{OB}$ in vivo.

We also analyzed the migratory properties of the infected cells traveling along the RMS before reaching the $\mathrm{OB}$ at the elbow level 
A

\begin{tabular}{|c|c|c|}
\hline \begin{tabular}{|l|l|l|l|l|l|} 
LTR & shR scr. \\
\end{tabular} & RFP & WPRE LTR \\
\hline 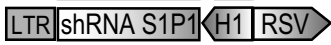 & $\overline{\text { EGFP }}$ & WPRE LTR \\
\hline
\end{tabular}

C

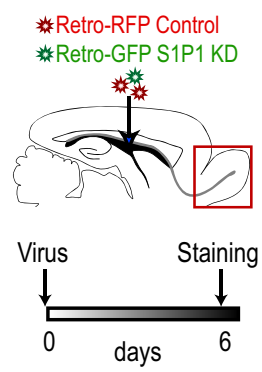

D

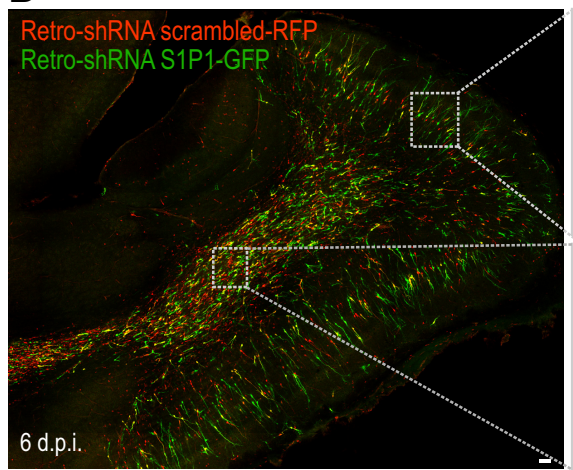

$\mathbf{F}$

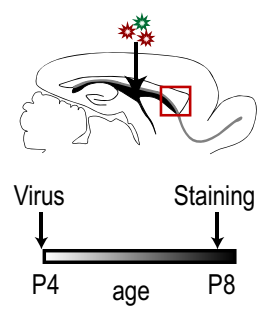

H

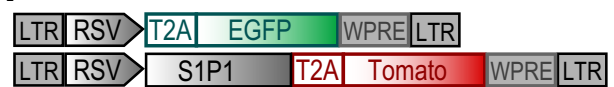

J

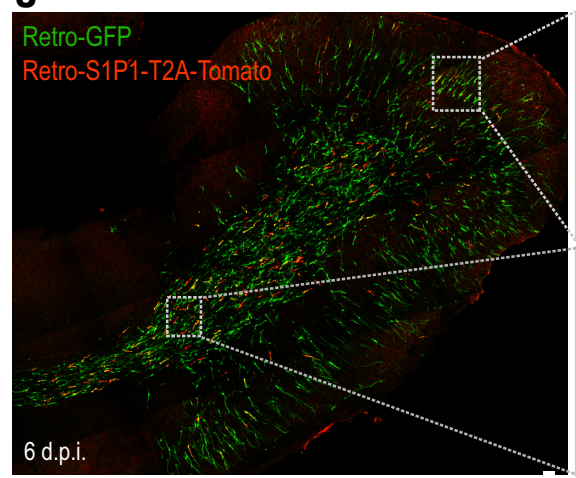

B

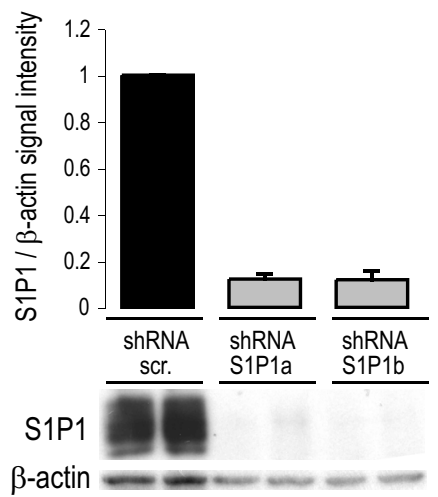

E
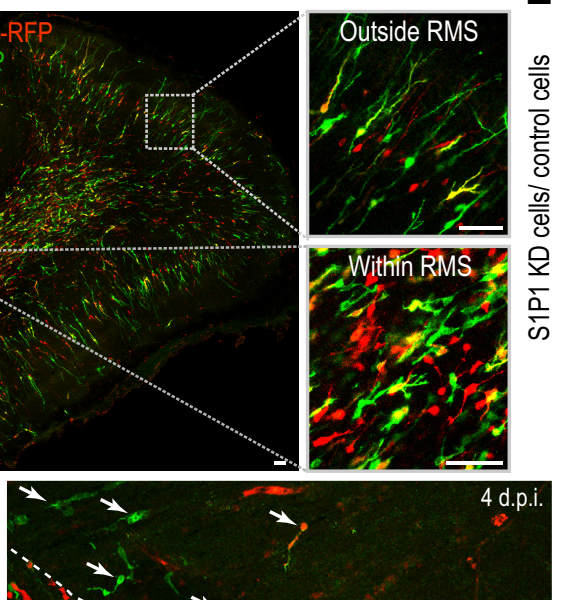

G
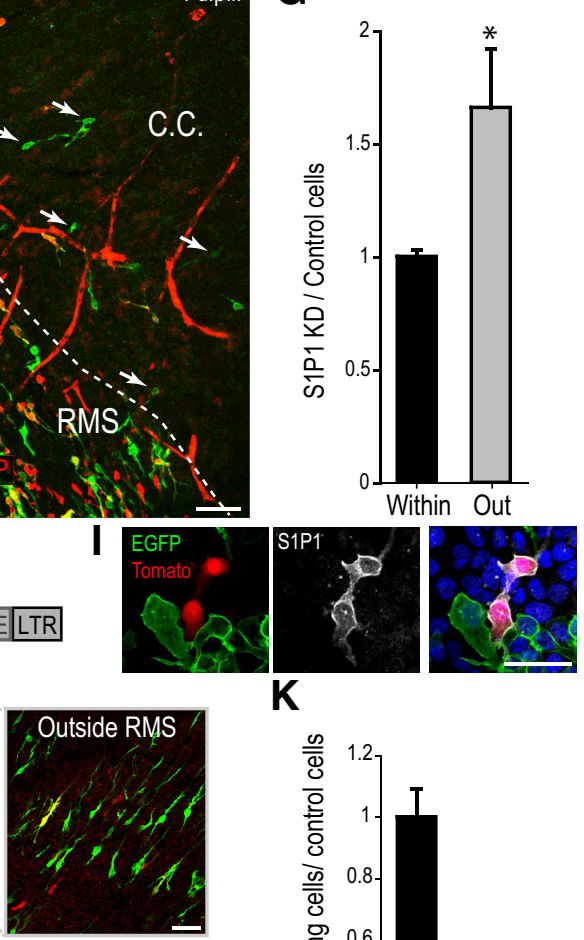

Within RMS

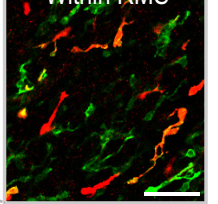

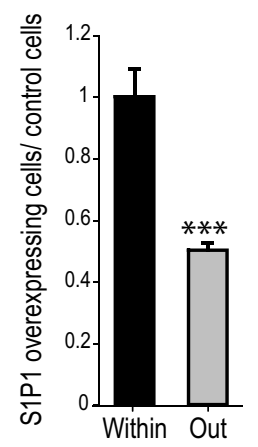

Figure 2. S1P1 expression levels regulate the fraction of neuroblasts outside the RMS. $A$, Scheme of the control and knock-down retroviral constructs used to infect SEZ-derived newborn cells by stereotactical brain injections. $\boldsymbol{B}$, Western blot assays with total protein extracts from HEK cells cotransfected with S1P1 and either a control plasmid expressing scrambled shRNA or shRNA against S1P1 ("a" and "b" are different sequences targeting S1P1). Top graph shows the quantification of the blot shown below. $\boldsymbol{C}$

(Fig. $4 F, G$ ). Neither the distance covered nor the net distance traveled was different between S1P1 knock-down and control cells (Fig. $4 H$ ). In this case, it was not possible to perform a statistical analysis using cells detaching from the RMS because of the low number of neuroblasts migrating radially in this area. Altogether, the reduction in S1P1 levels does not seem to affect the kinetics of migrating neuroblasts, but rather the time point when a cell switches its mode of migration.

\section{S1P1 regulates neuroblast cell adhesion} and chain detachment

To study the cellular mechanism responsible for the migratory effects observed in vivo, we analyzed the behavior of neuroblasts maintained in vitro under different conditions. For pharmacological experiments, we dissected the SEZ and plated

$\longleftarrow$

Experimental scheme. Mice were injected in the SEZ with a retroviral mixture and the $O B$ was imaged $6 \mathrm{~d}$ later. $D$, Confocal image of a sagittal brain section containing the $O B$ from a mouse injected with the viral mixture in the SEZ and killed $6 \mathrm{~d}$ later. Enlargements show infected cells (red, control; green, S1P1 knock-down) outside the RMS ${ }^{\mathrm{OB}}$ (top) and migrating within the RMS ${ }^{\mathrm{OB}}$ (bottom). E, Quantification of control and knock-down infected cells within and outside the RMS ${ }^{0 B}$ plotted as ratios between knock-down/control cells. A higher proportion of knock-down cells are found outside the RMS ${ }^{\mathrm{OB}}$ compared with control cells. $n=8$ mice for shRNAa (2317 and 5945 control and knock-down cells, respectively) and $n=7$ mice for shRNAb (941 and 3858 control and knock-down cells, respectively). ${ }^{* *} p=0.0006,{ }^{*} p=0.012, t$ test. $\boldsymbol{F}$, Experimental scheme. P4 mice were injected in the SEZ with a mixture of control and S1P1 knock-down virus and, $4 \mathrm{~d}$ later, the RMS at the level indicated with the red square was analyzed. The confocal picture on the right shows infected neuroblasts migrating within the RMS and outside the RMS in the corpus callosum toward the cortex (arrows indicate S1P1 KD cells outside the RMS). G, Quantification of control and knock-down infected cells within and outside the RMS plotted as ratios between knock-down/control cells. A higher proportion of knock-down cells exited the RMS in direction to the cortex. $n=4$ mice $(254$ and 635 control and knock-down cells, respectively). CC, Corpus callosum. ${ }^{*} p=0.0286$, Mann-Whitney test. $\boldsymbol{H}$, Scheme of the control and overexpressing retroviral constructs used to infect SEZ-derived newborn cells. I, Example of HEK cells infected with control (green) or S1P1 overexpression (red) viruses immunostained with anti-S1P1 antibodies (white), confirming the correct expression and membrane localization of the recombinant protein. Blue nuclei were stained with DAPI. J, Confocal image of a sagittal brain section from a mouse injected with the viral mixture in the SEZ and killed $6 \mathrm{~d}$ later. Enlargements show infected cells (green, control; red, S1P1 overexpression) outside (top) and within the RMS $^{O B}$ (bottom). $\boldsymbol{K}$, Quantification of control and S1P1overexpressing cells within and outside the RMS ${ }^{\circ \mathrm{B}}$ plotted as ratios between overexpression/control cells. A higher proportion of S1P1-overexpressing cells remained in the RMS $^{\mathrm{OB}}$ compared with control cells. $n=12$ mice (11583 and 3063 control and overexpressing cells, respectively). ${ }^{* * *} p=2.4 \mathrm{E}-5, t$ test. Scale bars, $50 \mu \mathrm{m}$. 

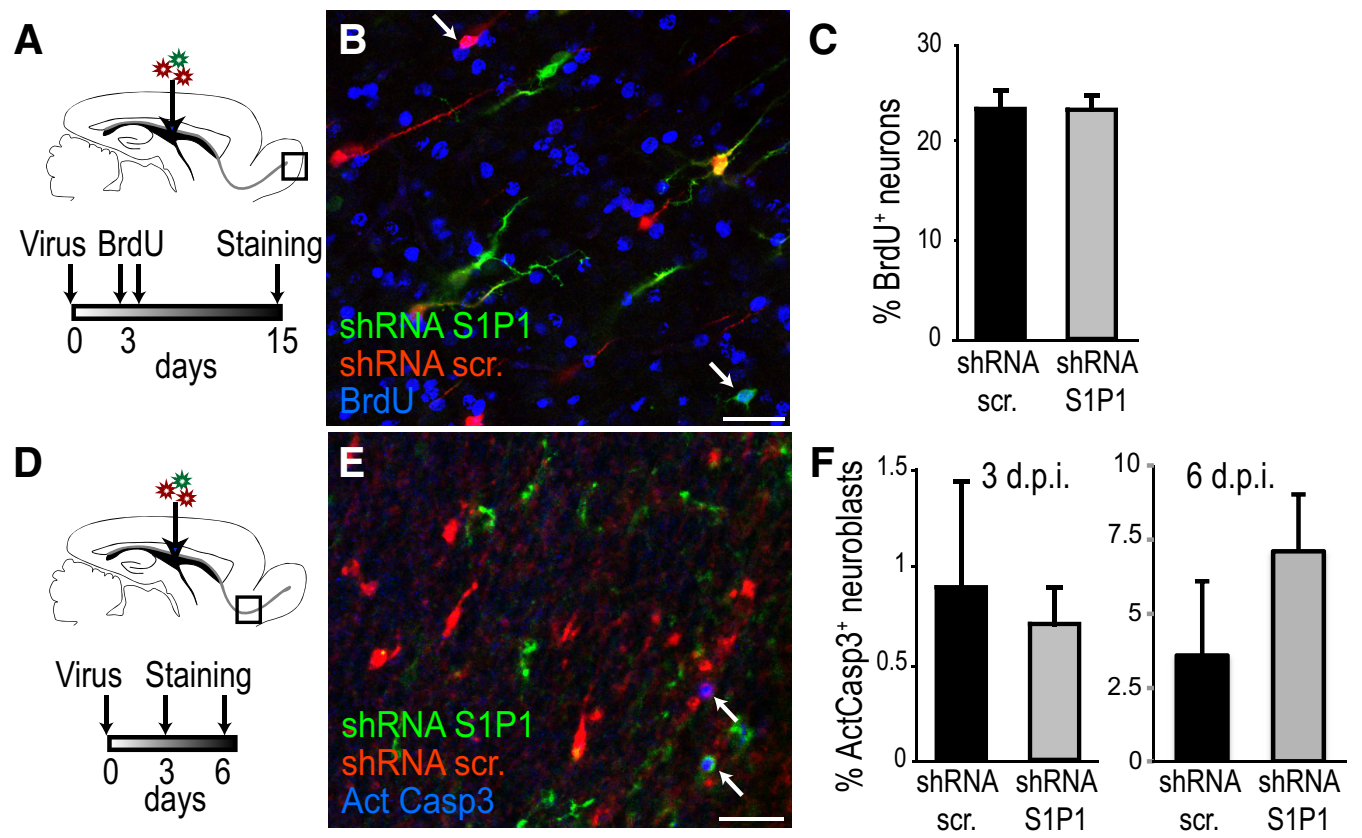

Figure 3. Proliferation and apoptosis of neuroblasts is unaltered after S1P1 knock-down. $A$, Experimental scheme. A mixture of control and S1P1-knock-down retroviruses was injected in the SEZ, followed by 2 intraperitoneal BrdU injections at 3 d.p.i. (with an interval of $6 \mathrm{~h}$ ), and mice were killed at 15 d.p.i. $B$, Examples of virally infected neurons in the $0 B$ positive for the proliferative marker BrdU (white arrows). C, Quantification of control and S1P1-knock-down cells positive for BrdU shows no difference in proliferation between groups ( $n=8,1151$ and 1323 control and knock-down cells, respectively). D, Experimental scheme. A mixture of control and S1P1-knock-down retroviruses was injected in the SEZ and the mice were killed at 3 or 6 d.p.i. $\boldsymbol{E}$, Examples of virally infected neuroblasts in the RMS positive for the apoptotic marker Active Casp-3 (white arrows). $F$, Quantification of control and S1P1-knock-down cells positive for Active Casp-3 in the RMS ${ }^{\text {OB }}$ at 3 d.p.i. . (left) and 6 d.p.i. (right) shows no difference in apoptosis between groups ( $n=4239$ and 1175 control and knock-down cells, respectively, $p=0.7$ for 3 d.p.i., $t$ test; $n=5231$ and 773 control and knock-down cells, respectively, $p=0.29$ for 6 d.p.i., $t$ test. Scale bars, $50 \mu \mathrm{m}$.

explants on top of an astrocytic monolayer before adding an agonist of S1P1 (CYM 5442), an antagonist (W146), or control medium. After $2 \mathrm{~d}$ in vitro, we fixed the explants and analyzed neuroblast migration (Fig. $5 A, B$ ). The results showed that, whereas the pharmacological activation of S1P1 induced cell attachment between neuroblasts, specific blockage of the receptor increased the number of neuroblasts migrating as single cells (Fig. $5 C, D$ ). To evaluate chain migration in vitro, we cultured SEZ explants in Matrigel, a 3D extracellular matrix gel (Wichterle et al., 1997). We incubated the explants with AAV-control virus (only expressing the fluorescent protein) or AAV-S1P1-expressing virus shortly before plating, and analyzed the migrating neuroblasts $4 \mathrm{~d}$ later (Fig. 5A). Neuroblasts overexpressing S1P1 formed chains more often than control cells. The overexpressing neuroblasts contacted neighboring cells while migrating, whereas control infected cells showed a lower tendency of aggregation (Fig. 5E,F). These results provide evidence that S1P1 modulates cell detachment and release from chain migration, thereby affecting the switch from tangential to radial migration.

\section{Astrocytes provide the ligand S1P that regulates neuroblast detachment in vitro}

The natural ligand of S1P1 is the bioactive lipid S1P, which is synthetized by phosphorylation of sphingosine by the kinases SK1 and SK2 (Maceyka et al., 2012). Therefore, we decided to investigate first whether these enzymes are present in the RMS/OB and, second, whether S1P is responsible for the observed effects mediated by S1P1. Immunostainings of SK1 and SK2 showed that both enzymes are expressed by astrocytes in the RMS and the OB (Fig. 6A), but no signal was detected in neuroblasts (data not shown). This suggests that $\mathrm{S} 1 \mathrm{P}$ acts in a paracrine fashion in S1P1-expressing neuroblasts. To determine whether S1P mediates S1P1-induced cell attachment, we used AAV viral infections and reduced S1P production in cultures. To knock down SK1 and SK2 simultaneously, we generated a construct in an AAV backbone containing two shRNAs (one targeting SK1 and the other SK2) under the control of independent promoters (U6 and H1, respectively) that efficiently knocked down both kinases (Fig. 6B, C). We infected astrocytes in culture with either the control or the double-knock-down virus, plated SEZ explants on top, and allowed the neuroblasts to migrate for $3 \mathrm{~d}$ (Fig. $6 D, E)$. The proportion of neuroblasts migrating as single cells was higher when the cells were contacting SK1/SK2 knock-down astrocytes (Fig. 6F). Because modifying the expression levels of the ligand mimicked the effects of altering receptor expression, we conclude that activation of S1P1 and its subsequent effect on neuroblast attachment is mediated by S1P.

\section{S1P1 deletion in the RMS downregulates the cell adhesion molecule NCAM and $\beta 1$ integrin}

Finally, we investigated possible downstream molecular mechanisms involved in S1P1-mediated cell attachment. To this end, we made use of a genetic approach that allowed us to reduce S1P1 expression in migrating neuroblasts in a more extensive way: we crossed S1P1 ${ }^{\text {loxP/loxP }}$ mice (Allende et al., 2003) with MashCRE ${ }^{\mathrm{ERT} 2}$ mice that express an inducible Cre in fast-dividing progenitors after tamoxifen treatment (Kim et al., 2011). Based on experiments using the reporter line Rosa26 Mash1CRE ${ }^{\mathrm{ERT} 2}$, we estimated that $\sim 60 \%$ of the neuroblast progenitors were targeted in mice treated with the highest viable dose of tamoxifen for $5 \mathrm{~d}$ (data not shown). As a control, we used S1P $1^{\text {loxP/loxP }}$ littermates negative for Cre (Fig. $7 A)$. We first estimated the number of neuroblasts in each 
A

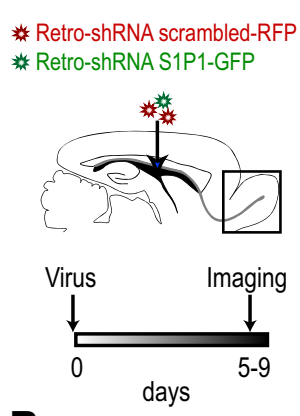

B
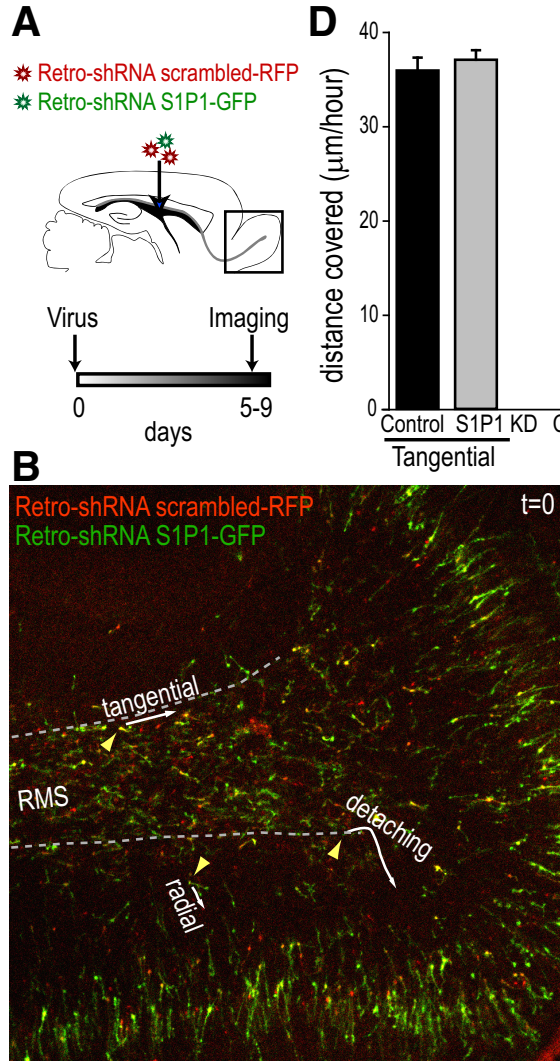

C
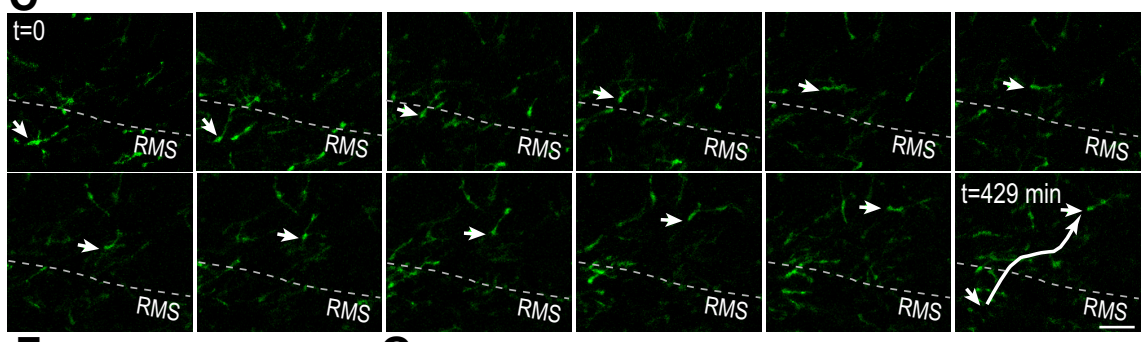

$\mathbf{F}$

$\overrightarrow{R M S}$

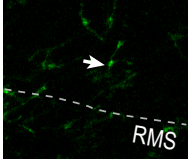

* Retro-shRNA scrambled-RFP Retro-shRNA S1P1-GFP
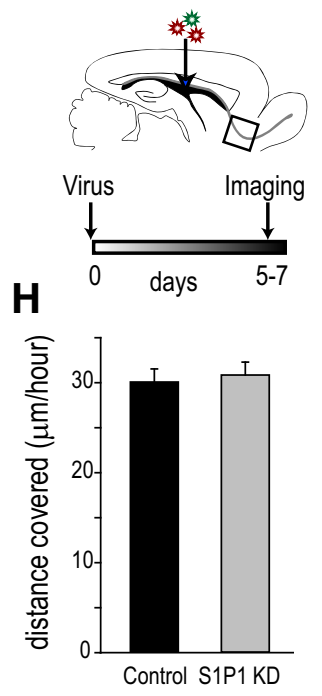

\section{G}
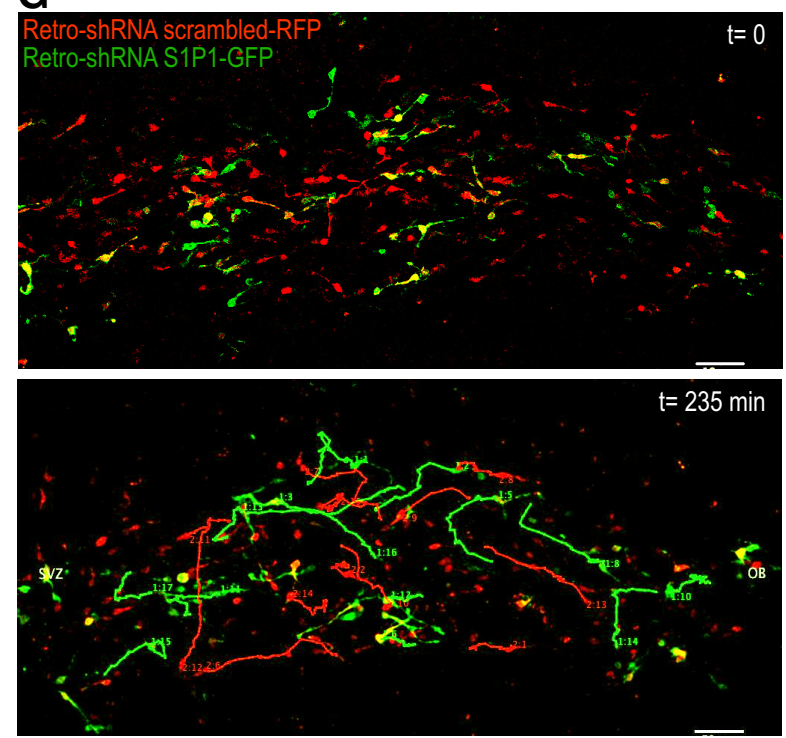

Figure 4. S1P1 knock-down triggers radial migration in the OB. $A$, Experimental scheme. A mixture of control and S1P1-knockdown retroviruses was injected in the SEZ and the mice were killed between 5 and 9 d.p.i. to perform time-lapse imaging in $0 B$ sections. $\boldsymbol{B}$, Initial (time $=0$ ) and final image (time $=351 \mathrm{~min}$ ) from one video exemplifying different types of migration of labeled neuroblasts: tangential, detaching, and radial. Yellow and blue arrowheads indicate the starting and the final location, respectively. White arrows show the trajectory of the cells. C, Example of a S1P1-knock-down neuroblast migrating out of the sample as a control for the RMS dissection procedure using doublecortin expression levels. Next, we determined S1P1 expression levels in both genotypes and confirmed that tamoxifen treatment reduced the expression of $\mathrm{S} 1 \mathrm{P} 1$ in the RMS of $\mathrm{S} 1 \mathrm{P} 1^{\operatorname{lox} P / \operatorname{lox} P}$ MashCRE $^{\text {ERT2 }}$ mice (Fig. $7 B$ ). This reduction led to a widening of the RMS ${ }^{\mathrm{OB}}$. When labeled with BrdU $4 \mathrm{~d}$ before staining, we noticed that the neuroblasts spread more at the tip of the bulb in S1P1 $1^{\text {loxP/loxP }}$ MashCRE ${ }^{\text {ERT2 }}$ mice than in controls (Fig. 7C,D). This observation is consistent with the notion that the lack of S1P1 in neuroblasts induces their dispersion from the RMS ${ }^{\mathrm{OB}}$ into the superficial layers of the $\mathrm{OB}$.

The broad deletion of S1P1 allowed us to measure differences in gene expression levels of several downstream candidate genes by quantitative realtime PCR. Based on an educated guess, we selected a number of genes involved in cell adhesion that are also present in the RMS (data from the Allen Mouse Brain Atlas, http://mouse.brain-map.org/) and measured their expression level in the RMS and the OB. Interestingly, several cell adhesion proteins were downregulated in the OB compared with the RMS in wild types, suggesting a general molecular mechanism by which neuroblast detachment and chain disassemble is facilitated in the OB. Such is the case for the neural cell adhesion molecule NCAM1: $71.9 \pm$ $1 \%$ reduction in the OB, VCAM: $65.9 \pm$ $3 \%$ reduction in the $\mathrm{OB}, \beta 1$ integrin: $56.3 \pm 3 \%$ reduction in the $\mathrm{OB}$, Cadherin $12: 63.4 \pm 0.8 \%$ reduction in the $\mathrm{OB}$,

RMS $^{\mathrm{OB}}$. D, Quantification of the distance covered per hour for control and S1P1-knock-down neuroblasts while they migrate tangentially within the RMS ${ }^{\mathrm{OB}}$ ( $n=104$ and 135 control and knock-down cells, respectively), detaching from the RMS ${ }^{\mathrm{OB}}$ ( $n=36$ and 73 control and knock-down cells, respectively), or radially outside of the RMS ${ }^{\mathrm{OB}}$ ( $n=17$ and 25 control and knock-down cells, respectively) shows no difference between cell types. $\boldsymbol{E}$, The proportion of S1P1-knock-down cells (over control neuroblasts) shows a significant increase when comparing cells migrating tangentially and radially ( $n=757$ and 1053 control and knock-down cells, respectively, from 9 independent videos). ${ }^{* * *} p=0.0009, t$ test. $\boldsymbol{F}$, Experimental scheme. A mixture of control and S1P1-knock-down retroviruses was injected in the SEZ and mice were killed between 5 and 7 d.p.i. to perform time-lapse imaging in the RMS (area indicated with the square). $\mathbf{G}$, Initial (time $=0$ ) and final image (time $=235 \mathrm{~min}$ ) from one video showing the trajectory of labeled neuroblasts. $\boldsymbol{H}$, Quantification of the distance covered per hour for control and S1P1-knock-down neuroblasts while they migrate within the RMS ( $n=80$ and 56 control and knock-down cells, respectively) shows no difference between cell types. Scale bars, $50 \mu \mathrm{m}$. 
A

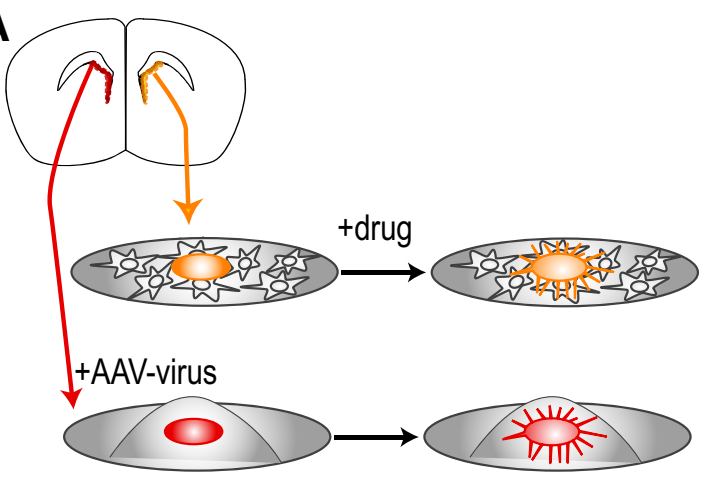

B
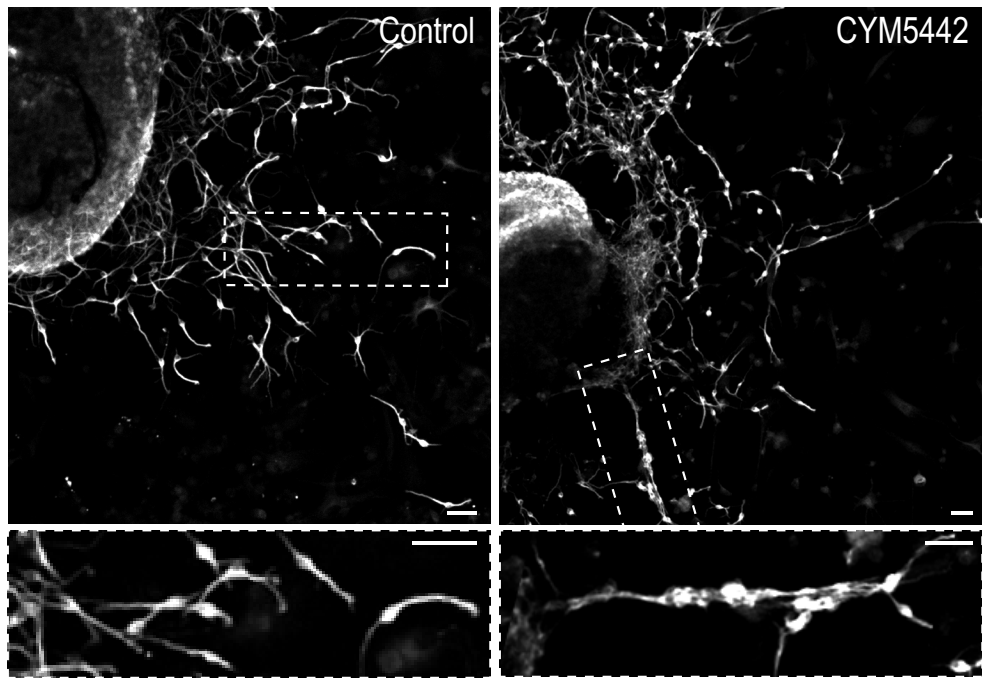

E

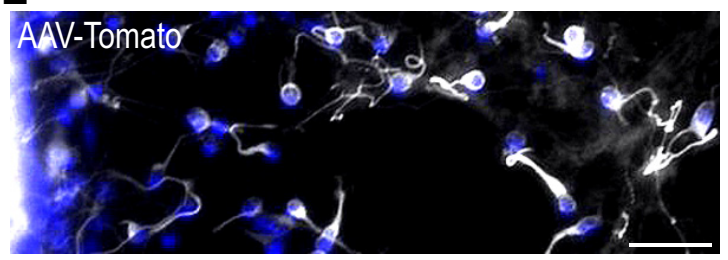

C

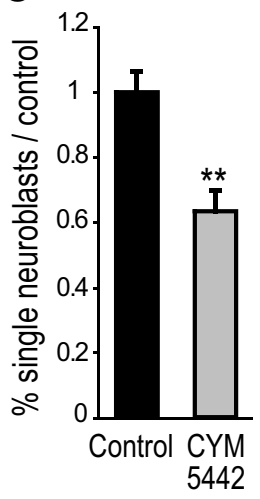

D

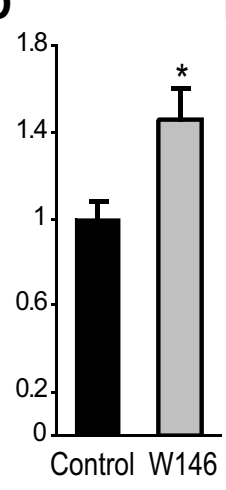

$\mathbf{F}$

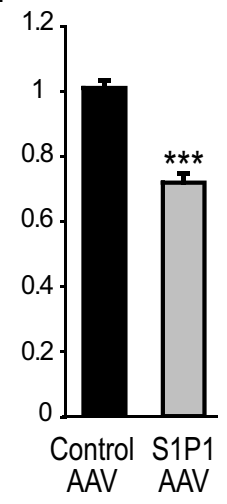

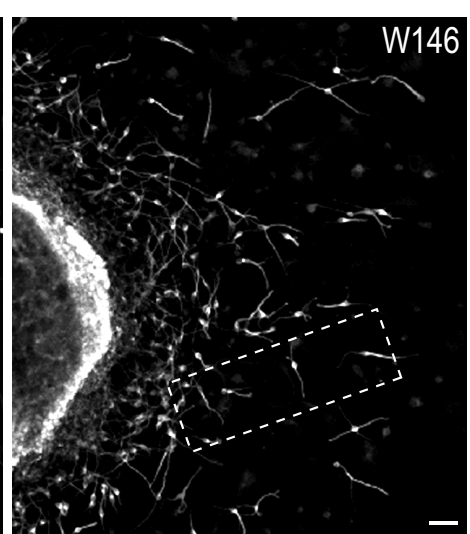
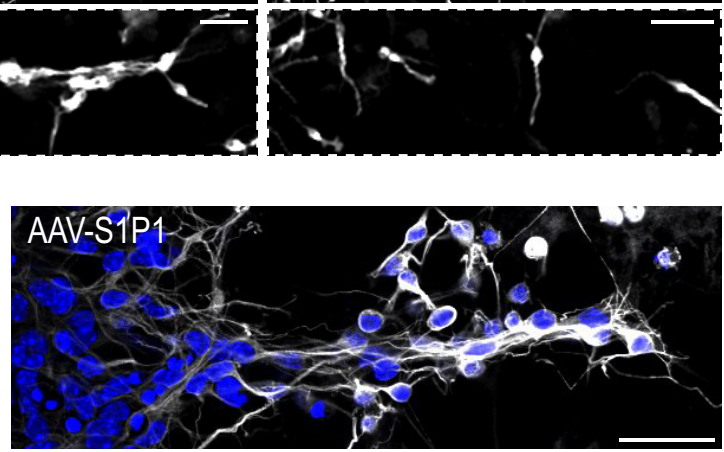

Figure 5. S1P1 regulates neuroblast cell adhesion. $A$, Experimental scheme. SEZ explants were plated on top of astrocytes and incubated with control medium, an agonist of S1P1 (CYM5442, $0.5 \mu \mathrm{M}$ ), or an antagonist of S1P1 (W146, $1 \mu \mathrm{m}$; top scheme in orange) or with either a control AAV-virus or an S1P1-overexpressing AAV-virus and plated in Matrigel (bottom scheme in red). Two to $4 \mathrm{~d}$ later, the explants were fixed and stained with a neuroblast marker. $\boldsymbol{B}$, Representative pictures of fixed explants stained with anti-tuj-1 and treated with control medium, CYM5442, or W146. Bottom images are an enlargement of the area indicated in the top. C, D, Quantification of neuroblasts migrating out of the explants as single cells in control or treatment conditions. Activating S1P1 resulted in enhanced cell-cell adhesion, whereas blocking the receptor induced neuroblast detachment $(n=3148$ and 3773 cells per group from 13-14 explants and 4870 and 3896 cells per group from 13-14 explants for $\boldsymbol{C}$ and $\boldsymbol{D}$, respectively). ${ }^{*} p=0.01,{ }^{* *} p=0.0004, t$ test. $\boldsymbol{E}$, Representative images from fixed explants incubated with control AAV-Tomato or AAV-S1P1-IRES-Tomato virus stained with anti-tuj-1 antibodies (white) and DAPI (blue). $F$, Quantification of cells migrating out of the explant as single cells for each group normalized to the control value ( $n=4214$ and 2707 cells per group from 19 to 20 explants). ${ }^{* * *} p=1$.E-9, $t$ test. Scale bars, $50 \mu \mathrm{m}$.

and Catenin betal: $85.4 \pm 0.6 \%$ reduction in the $\mathrm{OB}(n=3$ animals, values from RMS and OB normalized with DCX). Importantly, the expression levels of NCAM1 and $\beta 1$ integrin were significantly reduced in the RMS of S1P1 $1^{\text {loxP/loxP }}$ MashCRE ${ }^{\text {ERT2 }}$ mice after tamoxifen treatment, reaching values similar to those found in the $\mathrm{OB}$ of control and knock-out mice (Fig. 8A). Therefore, it is likely that the S1P1-induced downregulation of these cell adhesion molecules mediates, at least partially, the cellular effects observed for S1P1 in vivo and in vitro. Accordingly, immunostainings of PSA-NCAM indicated that it is highly expressed in neuroblasts migrating in chains within the RMS ${ }^{\mathrm{OB}}$ and downregulated in neuroblasts migrating as single cells outside the $\mathrm{RMS}^{\mathrm{OB}}$, which mimics the pattern of S1P1 expression (cf. Figs.
$8 B, 1 C)$. Furthermore, at the single-cell level, neuroblasts in the $\mathrm{RMS}^{\mathrm{OB}}$ infected with the S1P1-knock-down virus are not positive for PSA-NCAM, whereas control neuroblasts show high expression of the cell adhesion molecule (Fig. 8C,D).

In summary, our results support the following hypothesis: neuroblasts migrating in chains in the RMS express the S1P1 receptor, and its activation by astrocyte-derived S1P contributes to neurophilic cell adhesion. Once the cells reach the end of the RMS in the $\mathrm{OB}$, they cease to express $\mathrm{S} 1 \mathrm{P} 1$, which results in the downregulation of NCAM and $\beta 1$ integrin and the subsequent cell detachment from the migratory chains. Finally, single cells migrate radially to reach the proper neuronal layer in the $\mathrm{OB}$ and differentiate mainly into interneurons (Fig. 9). 
A
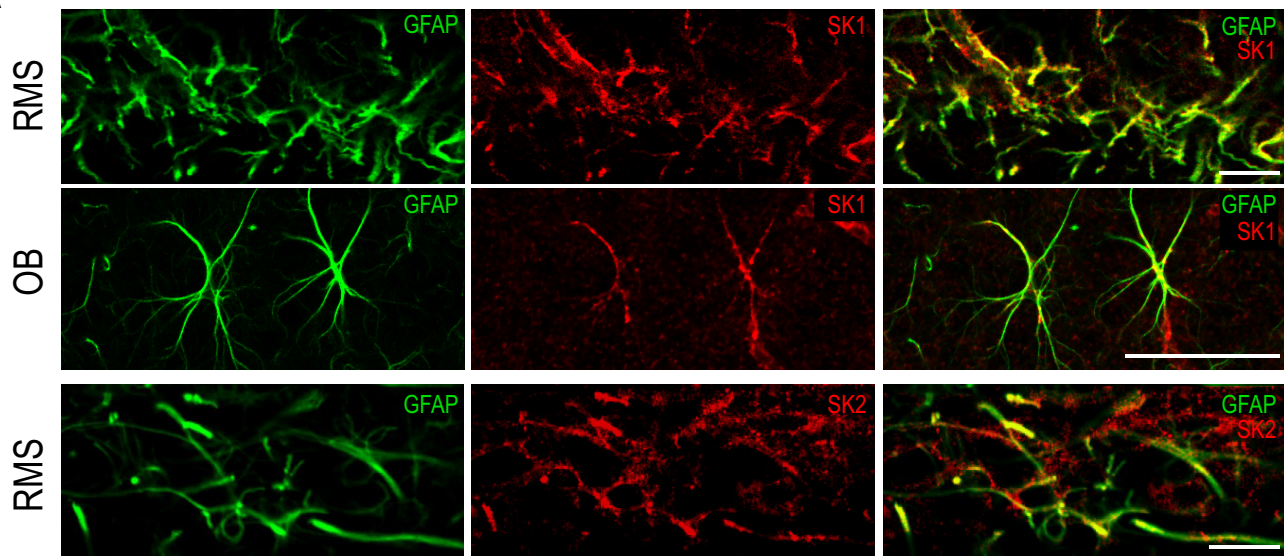

$\stackrel{\infty}{0}$
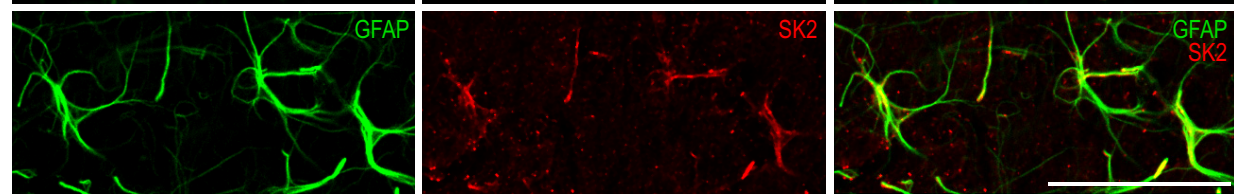

B

C

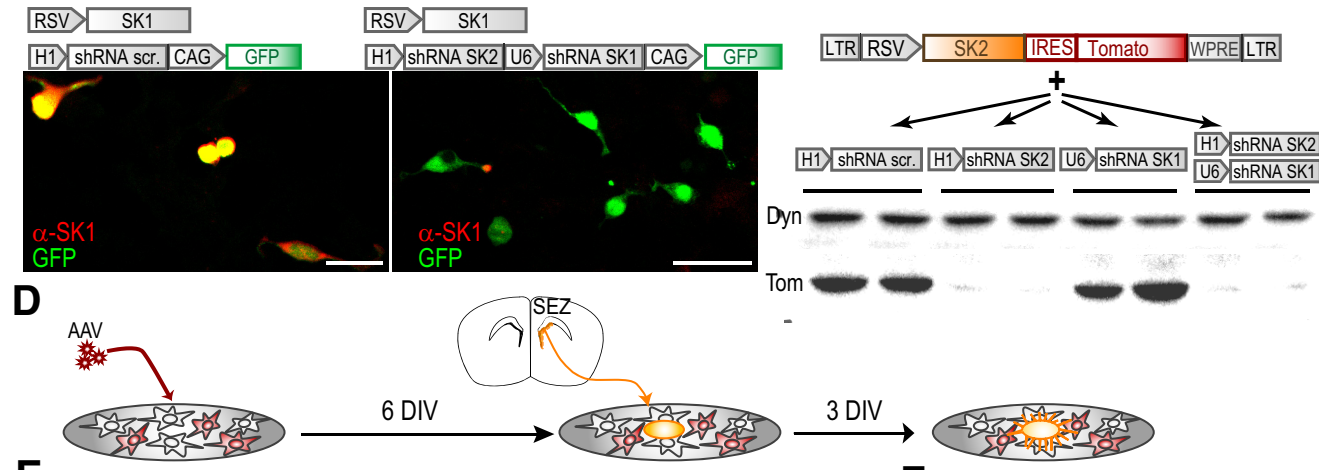

E

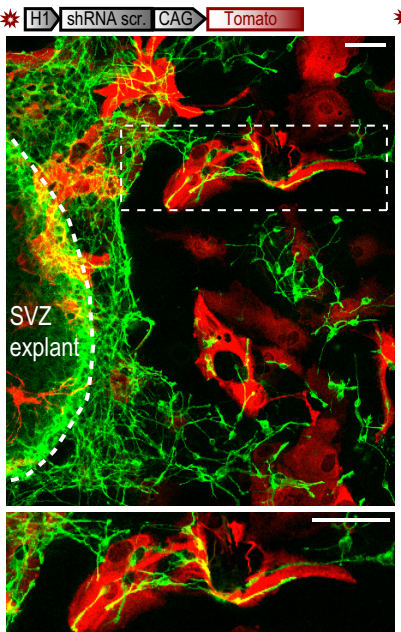

* H1) ShRNA SK2]U6) shRNA SK1 CAG Tomato

$\mathbf{F}$
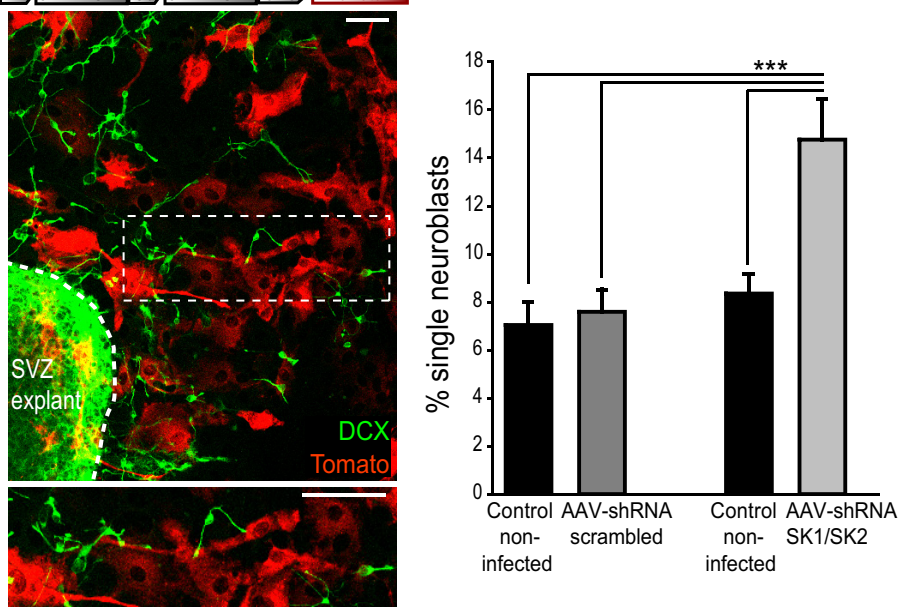

Figure 6. SK1/2 double knock-down in astrocytes reduces neuroblast cell adhesion. $A$, Confocal images of RMS and OB tissue sections showing the expression of SK1 (top, red) and SK2 (bottom, red) in astrocytes immunostained with GFAP (green). $\boldsymbol{B}$, Top, Scheme of the plasmid constructs that were transfected to HEK cells. Bottom, Examples of cells cotransfected with the indicated plasmids and immunostained with anti-SK1 antibodies. C, Western blots with protein extracts from HEK cells cotransfected with SK2-IRES-Tomato and a plasmid expressing shRNA scrambled (first and second lanes), shRNA against SK2 (third and fourth lanes), shRNA against SK1 (fifth and sixth lanes), or shRNA against SK2 and SK1 (seventh and eighth lanes). Because SK2 and Tomato sequences are encoded in the same transcript, an shRNA targeting SK2 will also silence Tomato. D, Experimental scheme. Primary astrocytic cultures were infected with AAV control virus (shRNA scrambled + Tomato) or AAV double SK1/2 knock-down virus (+ Tomato). Six days later, SEZ explants were plated on top of the infected astrocytes and fixed after $3 \mathrm{~d}$ in vitro. $\boldsymbol{E}$, Examples of explants plated on top of control (left) or double SK1/2 knock-down infected astrocytes (right), stained with a neuroblast marker (DCX in green) and anti-tomato (red). Bottom images are an enlargement of the area indicated in the top images. $F$, Quantification of the neuroblasts migrating out of the explant as single cells (shown as percentage) on top of noninfected astrocytes (black bars) or on top of infected astrocytes with either control or double SK1/2 knock-down virus (gray bars). Neuroblasts in contact with SK1/2 knock-down astrocytes tend to detach from each other more frequently than cells migrating on top of control astrocytes ( $n=699,3665,2743$, and 1317 neuroblasts per group, in the order shown in the graph). ${ }^{* * *} p<0.0001$, Kruskal-Wallis test. Scale bars, $50 \mu \mathrm{m}$. 
A

S1P1'x/x (Control) S1P1|x/x MashCRE ${ }^{\text {ERT2 }}$
Tamoxifen Dissection RMS/OB,

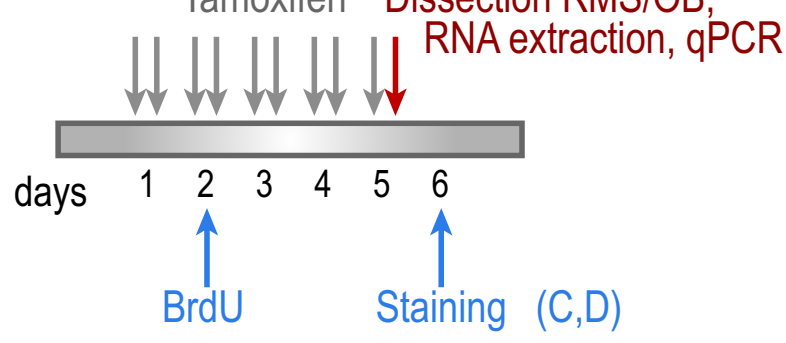

B
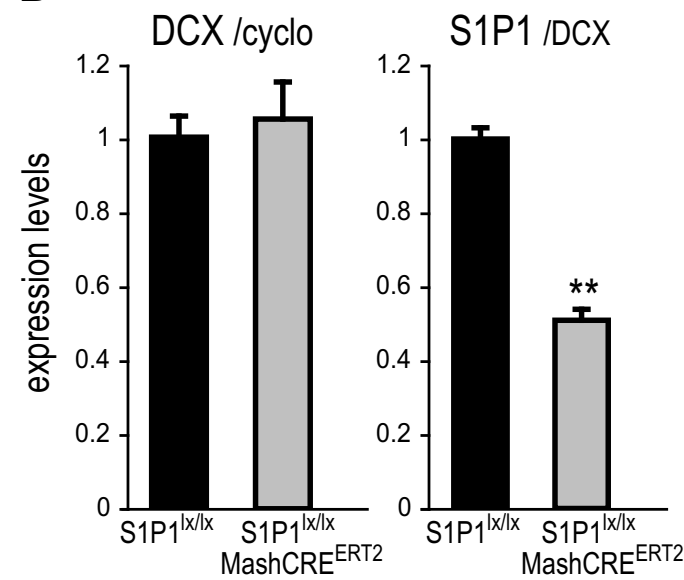

C

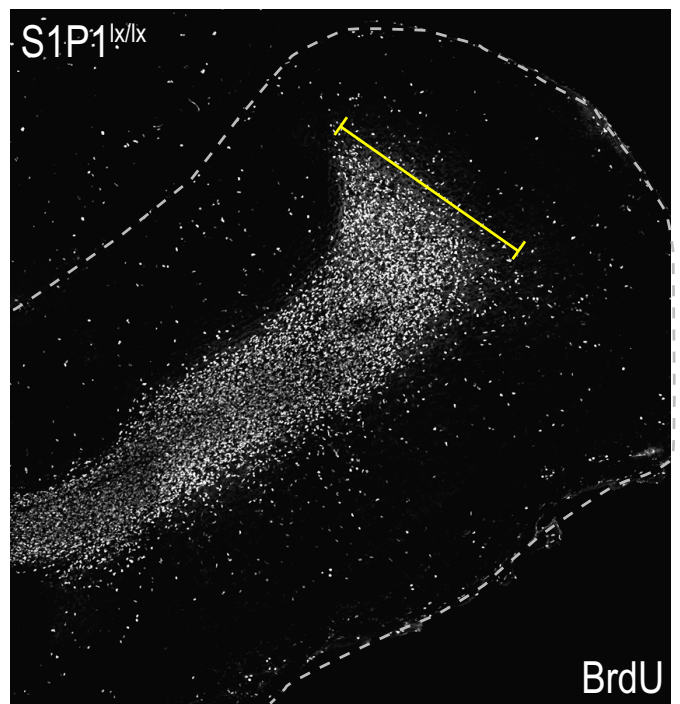

D
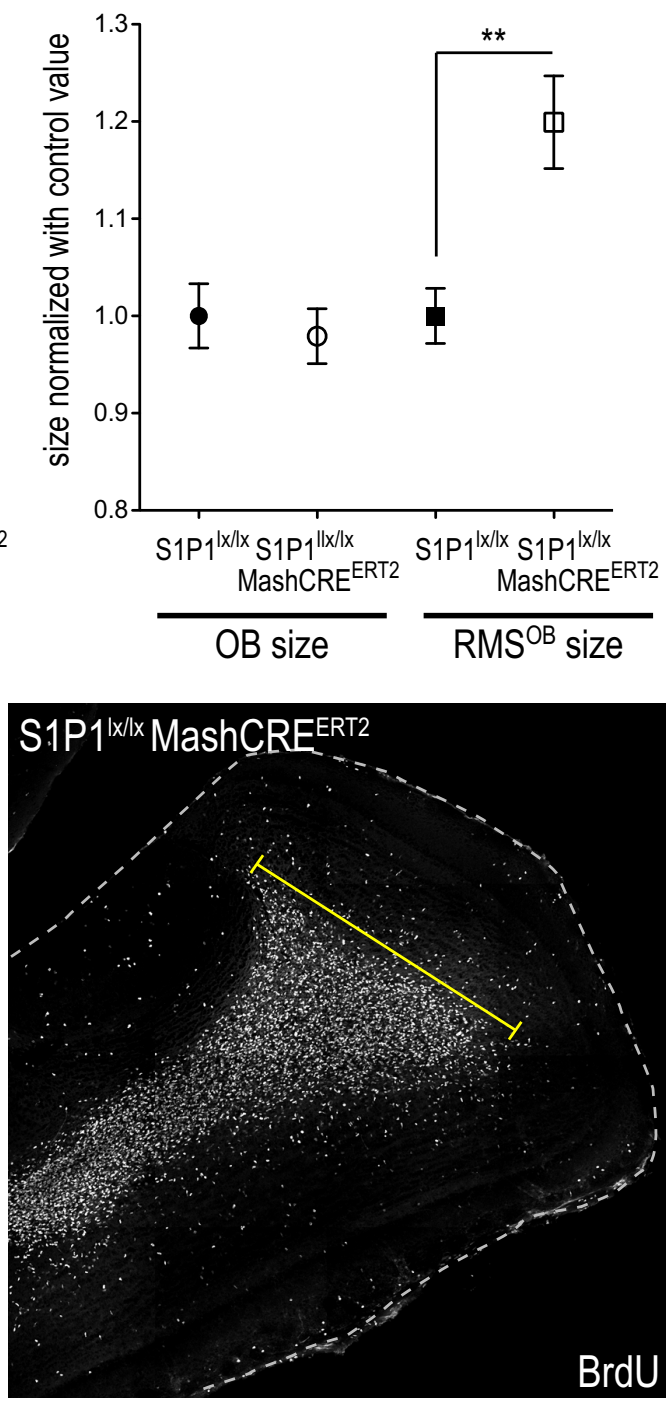

Figure 7. S1P1 genetic deletion in the RMS results in enhanced neuroblast dispersion in the OB. A, Experimental scheme. S1P1 ${ }^{\mid x / 1 x}$ (control) and S1P1 ${ }^{I x / 1 x}$ MashCRE ${ }^{\text {ERT2 }}$ mice were treated with tamoxifen twice per day for $5 \mathrm{~d}$ to delete S1P1 expression in the RMS. For one set of experiments, total RNA was extracted from the RMS and the OB and used as template for CDNA quantification. For another set of experiments, BrdU was injected at day 2, the mice were perfused, and brains were analyzed at day 6. B, Quantitative real-time PCR using RMS samples revealed similar expression levels of DCX (normalized to cyclophilin values), but reduced S1P1 expression (normalized to DCX values) in S1P1 ${ }^{\text {loxP } / \text { loxP }}$ MashCRE ${ }^{\text {ERT2 }}$ compared with control mice $\left(n=4-8\right.$ mice per group). ${ }^{* *} p=$ 0.0044 , Mann-Whitney test. C, Examples of BrdU stainings in sections containing the $\mathrm{OB}$ showing the width of the RMS ${ }^{\mathrm{OB}}$ as indicated by the yellow bars. D, Quantification of the bulb size and the size of RMS ${ }^{\mathrm{OB}}$ in control and S1P1 ${ }^{\text {loxP/loxP }}$ MashCRE ${ }^{\mathrm{ERT2}}$ mice $\left(n=13\right.$ mice per group). ${ }^{* *} p=0.001, t$ test.

\section{Discussion}

The function of each neuron is highly determined by the position it occupies within a neuronal circuit. Frequently, newborn neurons must travel long distances from their birthplace to their predetermined final location and, to do so, they use different modes of migration. The postnatal SEZ/RMS/OB axis represents an ideal system with which to study this process, but only a few studies have addressed how neuroblasts switch from tangential to radial migration in the RMS/OB. An important step in this process is the detachment of chain-migrating cells in the RMS ${ }^{\mathrm{OB}}$ to initiate radial migration toward the granular and periglomerular layers of the OB. According to a current hypothesis, the switch 
A

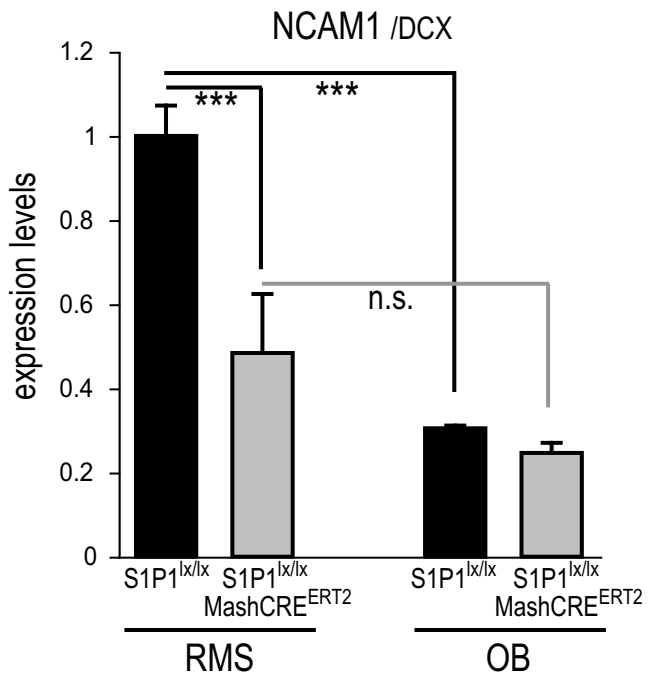

B
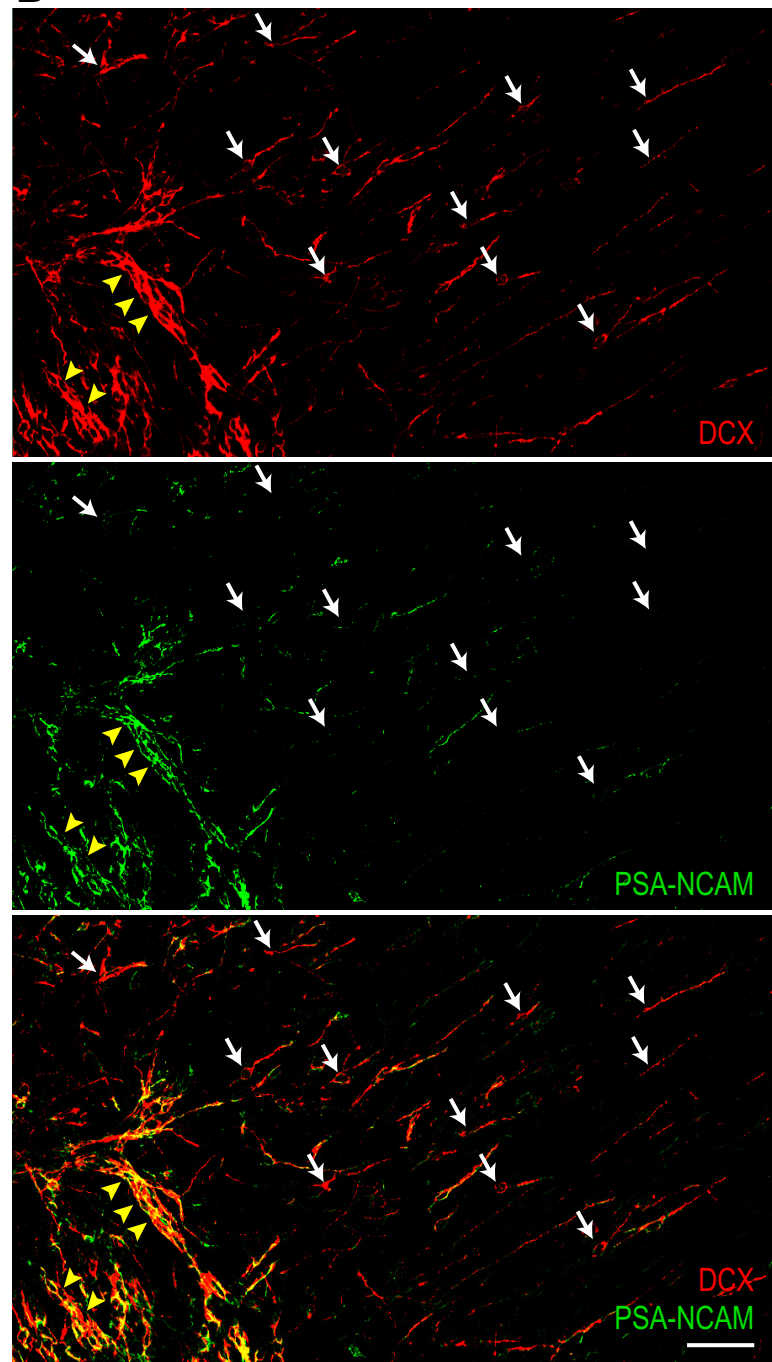

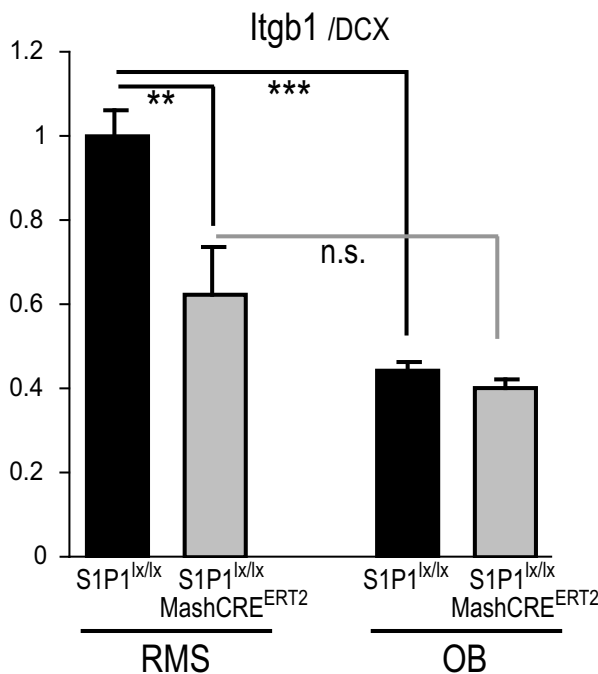

C Retro-shRNA scrambled-RFP Retro-shRNA S1P1-GFP
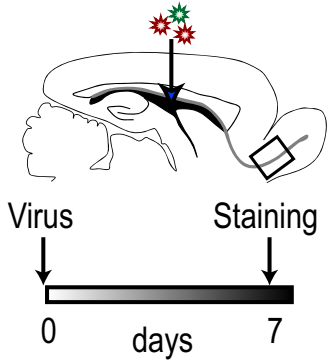

D
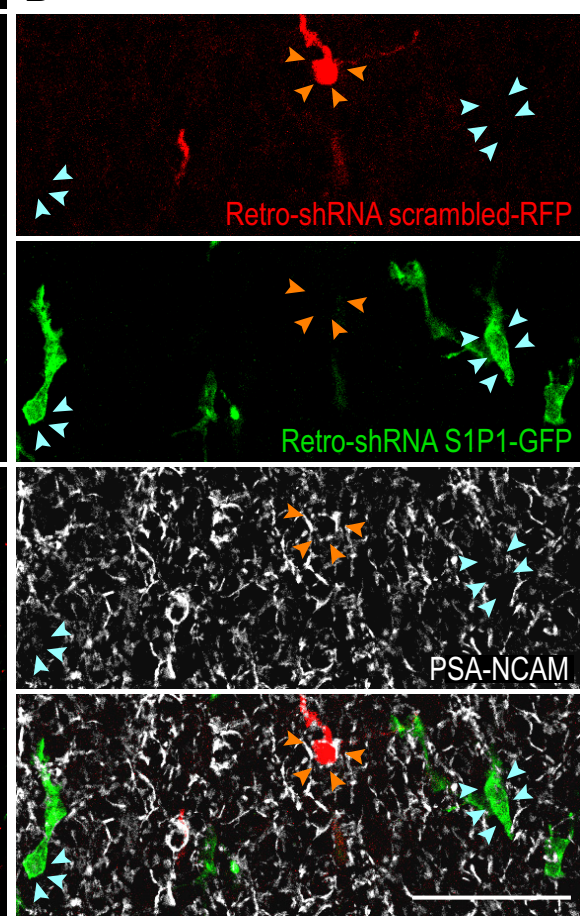

Figure 8. S1P1 deletion in the RMS downregulates the cell adhesion molecule NCAM1 and $\beta 1$ integrin. $A$, NCAM1 and $\beta 1$ integrin (Itgb1) expression levels (normalized to DCX values) were quantified in the RMS and OB of S1P1 ${ }^{1 \mathrm{x} / \mathrm{x}}$ and S1P1 ${ }^{\mathrm{Ix} / \mathrm{x}}$ MashCRE-ERT2 mice. In control mice, NCAM1 and Itgb1 expression levels were reduced in the $0 \mathrm{~B}$ compared with the RMS, whereas knock-out mice showed reduced levels of NCAM1 and Itgb1 both in the RMS and the OB (one-way ANOVA followed by Bonferroni's multiple-comparisons test). ${ }^{* *} p<0.0001$; ${ }^{* *} p<0.01 . \boldsymbol{B}$, Immunostaining with anti-DCX (red) and anti-PSA-NCAM (green) antibodies in OB tissue sections showing a high expression of PSA-NCAM in neuroblasts migrating in chains (yellow arrowheads) and a low expression in neuroblasts migrating radially as single cells (white arrows). C, Experimental scheme. Mice were injected in the SEZ with a mixture of control and S1P1 knock-down virus and, $7 \mathrm{~d}$ later, cells migrating in the RMS at the level indicated with the square were analyzed by immunostainings with anti-PSA-NCAM antibodies. D. Example of a control-infected cell (red) positive for PSA-NCAM (white) is indicated by the orange arrowheads and examples of S1P1 knock-down infected cells (green) negative for PSA-NCAM (white) are pointed out by light blue arrowheads. Scale bars, $50 \mu \mathrm{m}$. 

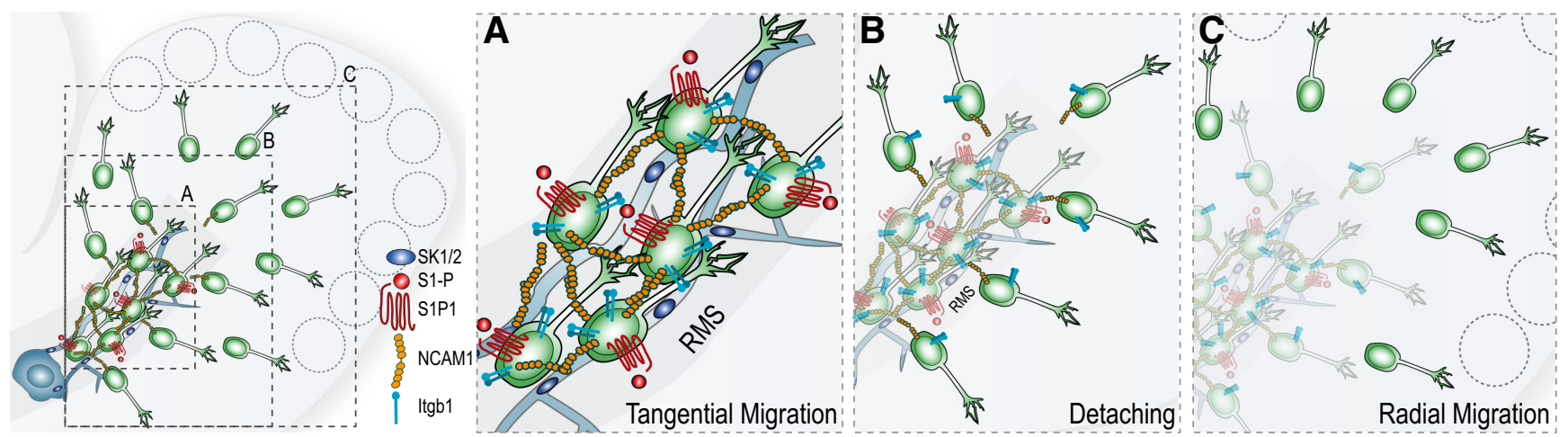

Figure 9. Summary. $A$, Neuroblasts (green cells) migrating in chains in the RMS express high levels of S1P1, PSA-NCAM, and $\beta 1$ integrin. S1P is secreted by the surrounding astrocytes (blue cells) and activates S1P1, resulting in strong cell adhesion. $\boldsymbol{B}$, When neuroblasts reach the $\mathrm{OB}$, they stop expressing S1P1, which leads to a downregulation of NCAM1 and $\beta 1$ integrin and subsequent cell detachment from migrating chains. C, Neuroblasts lacking S1P1 and exhibiting low levels of PSA-NCAM and $\beta 1$ integrin are able to initiate single-cell radial migration to eventually reach their final position in the $\mathrm{OB}$.

from tangential to radial migration is controlled by chemoattractive forces driven by extracellular matrix proteins in the outer layers of the OB (Hack et al., 2002; Saghatelyan et al., 2004; Ng et al., 2005). We now provide evidence for a mechanism that extends the above depicted scenario: we propose a molecular program by which neuroblasts downregulate the expression of cell adhesion molecules to switch from tangential to radial migration when they reach the end of the RMS ${ }^{\mathrm{OB}}$ in the OB. In this study, we identified one key component of this mechanism: the S1P1 receptor.

Our in vivo experiments using fluorescent retroviruses revealed that the presence of S1P1 contributes to maintain the neuroblasts within the RMS ${ }^{\mathrm{OB}}$, whereas its downregulation facilitates their radial migration toward the outer layers of the OB. Using acute organotypic slices, we analyzed the migratory behavior of control and mutant neuroblasts in their natural environment and found that the lack of S1P1 prompts the switch from tangential to radial migration, supporting the idea that this is the physiological role of S1P1 in postnatal neurogenesis. Indeed, although S1P1 is highly expressed during tangential migration, it is downregulated in radially migrating neuroblasts in the OB. The switch from tangential to radial migration is orchestrated by multiple factors. Opposite signals directed to retain or release the neuroblasts within the RMS are coordinated to precisely determine the route of a newborn neuron. For example, whereas molecules such as PSA-NCAM, integrins, Erb4, plexin-B2, and VEGF contribute to the assembly and maintainance of tangential migration (Chazal et al., 2000; Anton et al., 2004; Belvindrah et al., 2007; Wittko et al., 2009; Saha et al., 2012), other signaling factors such as tenascin $\mathrm{R}$, prokineticin-2, and reelin promote detachment of newborn neurons from cell chains to initiate radial migration (Hack et al., 2002; Saghatelyan et al., 2004; Ng et al., 2005; David et al., 2013). It is noteworthy that the effect of S1P1 reduction is confined to brain areas where radial migration normally takes place. Therefore, it can be inferred that S1P1 triggers radial migration in conjunction with other signaling pathways.

To investigate the underlying cellular mechanism, we performed in vitro experiments using SEZ-derived explants and observed that the activity of S1P1 regulates the cell-adhesion properties of neuroblasts. Our data based on pharmacological treatments and virus-mediated alteration of gene expression demonstrated that S1P1 acts as a positive signal for cell-cell attachment. Therefore, chain disassembly and detachment of individually migrating cells resulting in the shift between the two modes of migration requires the downregulation of S1P1. Furthermore, S1P, the natural ligand of S1P1, is the likely mediator of this cellular effect: neuroblasts migrating on top of SK1- and SK2-depleted astrocytes tend to detach from each other and migrate as single cells. Our immunostainings suggest that S1P acts in a paracrine fashion and that the surrounding astrocytes, which express SK1 and SK2, are a source of the ligand. Indeed, this bioactive lipid can be released to the extracellular medium in different systems and cell types, including astrocytes (Bassi et al., 2006; Sato et al., 2007). The transmembrane transport of S1P is mediated by the ABC type transporters ABCA1 and ABCC1 (Mitra et al., 2006; Sato et al., 2007), as well as by Spns2 (Fukuhara et al., 2012; Hisano et al., 2012). Along the RMS, there is a high density of astrocytic processes intercalated among neuroblasts and aligned with migrating chains (Lois et al., 1996). Within the $\mathrm{OB}$, this mesh of astrocytes decreases in density in the regions where radial migration initiates (Whitman et al., 2009). It is thus tempting to speculate that a reduction in the number of astrocytes closely associated with neuroblasts can in itself cause a decrease in S1P levels. Therefore, not only the downregulation of S1P1, but also insufficient ligand to activate the receptor, might contribute to cell detachment and the switch to radial migration.

We also examined putative molecular candidates acting downstream of S1P1 in migrating neuroblasts. Our experiments revealed two interesting results: (1) several adhesion molecules expressed in neuroblasts are normally downregulated in the $\mathrm{OB}$ and (2) S1P1 is responsible for the gene expression decrease of at least two of them: NCAM1 and $\beta 1$ integrin. Previous studies showed that neuroblasts in the RMS of NCAM-deficient mice display a less pronounced degree of chain-like arrangement (Chazal et al., 2000; Battista and Rutishauser, 2010). Furthermore, in vivo and in vitro experiments showed that the lack of PSA in neuroblasts (polysialylation occurs only in NCAM) results in loose cell-cell contact and chain dispersion (Chazal et al., 2000; $\mathrm{Hu}, 2000$; Battista and Rutishauser, 2010). There is also evidence that $\beta 1$ integrins are involved in the formation and cohesion of cell chains in the RMS (Emsley and Hagg, 2003; Belvindrah et al., 2007). Therefore, it is likely that the observed reduction of NCAM 1 and $\beta 1$ integrin in the $\mathrm{OB}$ is caused by the physiological downregulation of S1P1 and that the reduction of cell adhesion molecules mediates the effects on cell detachment. In agreement with this hypothesis, whereas the loss of PSA-NCAM affects tangential migration of neuroblasts along the RMS, radial migration within the bulb does not require this polysialylated protein (Ono 
et al., 1994; Hu et al., 1996). In addition to our findings, other molecules are probably also involved in S1P1 downstream signaling. In this study, we performed a biased screen focused on cell adhesion molecules. A more general approach such as a microarray or RNAseq might identify other unexpected players in the future.

Consistent with our results, previous in vitro experiments have shown that S1P induces cell aggregation of embryonic neural progenitor cells (Harada et al., 2004) and S1P1 was found to regulate cell adhesion also in other systems. Indeed, during angiogenesis, S1P1 activation induces vascular endothelial cell adherent junction assembly via cell adhesion molecules such as $N$-cadherin and VE-cadherin (Lee et al., 1999; Paik et al., 2004; Gaengel et al., 2012). Similarly, in the immune system, the adhesion properties of mature B cells can be regulated by S1P1 expression via integrin activation (Halin et al., 2005). At the same time, S1P acts as a chemoattractant through S1P1 in T and B cells to induce lymphoid organ egress (Matloubian et al., 2004). In the spinal cord, S1P was proposed to also function through a chemotactic mechanism because transplanted embryonic neural progenitors lacking S1P1 showed impaired migration toward spinal cord injury sites (Kimura et al., 2007). However, in the RMS/ $\mathrm{OB}, \mathrm{S} 1 \mathrm{P}$ action through S1P1 seems to act in a different way, namely by regulating cell adhesion of postnatally born migrating cells.

Despite the fact that S1P1 is highly expressed in the brain (Liu and Hla, 1997; Chae et al., 2004), only a few studies have addressed the role of this receptor in the CNS and most of them used in vitro systems (Edsall et al., 1997; Harada et al., 2004; Callihan and Hooks, 2012; Guo et al., 2013). S1P1 is already present during embryonic development and, interestingly, its expression in the telencephalon is restricted to the ventricular zone, where all neural progenitors reside, suggesting a role in neurogenesis (McGiffert et al., 2002). A global deletion of S1P1 or a double knock-out of SK1/2 causes embryonic lethality at $\sim$ E12.5 due to vascular defects. In addition, these null mice also show severe defects in neurogenesis, namely enhanced apoptosis and reduced mitosis in the neuroepithelium (Liu et al., 2000; Mizugishi et al., 2005). However, further studies using more specific approaches are needed to unequivocally address the role of S1P1 during embryonic neurogenesis. The S1P axis has been studied extensively in other systems and has been related to a number of pathological conditions (Chi, 2011; Maceyka et al., 2012). Moreover, a functional antagonist of S1P receptors known as Fingolimod is now used routinely in the treatment of relapsingremitting multiple sclerosis (Brinkmann et al., 2010) and several other S1P modulators are in clinical trials to treat different diseases (Kunkel et al., 2013). Given that these drugs are administered systemically and can cross the brain-blood barrier (Foster et al., 2007), it is important to understand the pleiotropic effects of S1P1 in the CNS.

\section{References}

Allende ML, Yamashita T, Proia RL (2003) G-protein-coupled receptor S1P1 acts within endothelial cells to regulate vascular maturation. Blood 102:3665-3667. CrossRef Medline

Anton ES, Ghashghaei HT, Weber JL, McCann C, Fischer TM, Cheung ID, Gassmann M, Messing A, Klein R, Schwab MH, Lloyd KC, Lai C (2004) Receptor tyrosine kinase ErbB4 modulates neuroblast migration and placement in the adult forebrain. Nat Neurosci 7:1319-1328. CrossRef Medline

Bassi R, Anelli V, Giussani P, Tettamanti G, Viani P, Riboni L (2006) Sphingosine-1-phosphate is released by cerebellar astrocytes in response to bFGF and induces astrocyte proliferation through Gi-protein-coupled receptors. Glia 53:621-630. CrossRef Medline
Battista D, Rutishauser U (2010) Removal of polysialic acid triggers dispersion of subventricularly derived neuroblasts into surrounding CNS tissues. J Neurosci 30:3995-4003. CrossRef Medline

Bayer SA (1983) 3H-thymidine-radiographic studies of neurogenesis in the rat olfactory bulb. Exp Brain Res 50:329-340. Medline

Belvindrah R, Hankel S, Walker J, Patton BL, Müller U (2007) Betal integrins control the formation of cell chains in the adult rostral migratory stream. J Neurosci 27:2704-2717. CrossRef Medline

Brinkmann V, Billich A, Baumruker T, Heining P, Schmouder R, Francis G, Aradhye S, Burtin P (2010) Fingolimod (FTY720): discovery and development of an oral drug to treat multiple sclerosis. Nat Rev Drug Discov 9:883-897. CrossRef Medline

Callihan P, Hooks SB (2012) Sphingosine-1-phosphate signaling in neural progenitors. Methods Mol Biol 874:193-200. CrossRef Medline

Carleton A, Petreanu LT, Lansford R, Alvarez-Buylla A, Lledo PM (2003) Becoming a new neuron in the adult olfactory bulb. Nat Neurosci 6:507518. Medline

Chae SS, Proia RL, Hla T (2004) Constitutive expression of the S1P1 receptor in adult tissues. Prostaglandins Other Lipid Mediat 73:141-150. CrossRef Medline

Chazal G, Durbec P, Jankovski A, Rougon G, Cremer H (2000) Consequences of neural cell adhesion molecule deficiency on cell migration in the rostral migratory stream of the mouse. J Neurosci 20:1446-1457. Medline

Chi H (2011) Sphingosine-1-phosphate and immune regulation: trafficking and beyond. Trends Pharmacol Sci 32:16-24. CrossRef Medline

Choi JW, Gardell SE, Herr DR, Rivera R, Lee CW, Noguchi K, Teo ST, Yung YC, Lu M, Kennedy G, Chun J (2011) FTY720 (fingolimod) efficacy in an animal model of multiple sclerosis requires astrocyte sphingosine 1-phosphate receptor 1 (S1P1) modulation. Proc Natl Acad Sci U S A 108:751-756. CrossRef Medline

David LS, Schachner M, Saghatelyan A (2013) The extracellular matrix glycoprotein tenascin-R affects adult but not developmental neurogenesis in the olfactory bulb. J Neurosci 33:10324-10339. CrossRef Medline

Edsall LC, Pirianov GG, Spiegel S (1997) Involvement of sphingosine 1-phosphate in nerve growth factor-mediated neuronal survival and differentiation. J Neurosci 17:6952-6960. Medline

Emsley JG, Hagg T (2003) alpha6beta1 integrin directs migration of neuronal precursors in adult mouse forebrain. Exp Neurol 183:273-285. CrossRef Medline

Foster CA, Howard LM, Schweitzer A, Persohn E, Hiestand PC, Balatoni B, Reuschel R, Beerli C, Schwartz M, Billich A (2007) Brain penetration of the oral immunomodulatory drug FTY720 and its phosphorylation in the central nervous system during experimental autoimmune encephalomyelitis: consequences for mode of action in multiple sclerosis. J Pharmacol Exp Ther 323:469-475. CrossRef Medline

Fukuhara S, Simmons S, Kawamura S, Inoue A, Orba Y, Tokudome T, Sunden Y, Arai Y, Moriwaki K, Ishida J, Uemura A, Kiyonari H, Abe T, Fukamizu A, Hirashima M, Sawa H, Aoki J, Ishii M, Mochizuki N (2012) The sphingosine-1-phosphate transporter Spns2 expressed on endothelial cells regulates lymphocyte trafficking in mice. J Clin Invest 122:14161426. CrossRef Medline

Gaengel K, Niaudet C, Hagikura K, Laviña B, Muhl L, Hofmann JJ, Ebarasi L, Nyström S, Rymo S, Chen LL, Pang MF, Jin Y, Raschperger E, Roswall P, Schulte D, Benedito R, Larsson J, Hellström M, Fuxe J, Uhlén P, et al. (2012) The sphingosine-1-phosphate receptor S1PR1 restricts sprouting angiogenesis by regulating the interplay between VE-cadherin and VEGFR2. Dev Cell 23:587-599. CrossRef Medline

Gonzalez-Cabrera PJ, Cahalan SM, Nguyen N, Sarkisyan G, Leaf NB, Cameron MD, Kago T, Rosen H (2012) S1P(1) receptor modulation with cyclical recovery from lymphopenia ameliorates mouse model of multiple sclerosis. Mol Pharmacol 81:166-174. CrossRef Medline

Guo H, Zhao Z, Yang Q, Wang M, Bell RD, Wang S, Chow N, Davis TP, Griffin JH, Goldman SA, Zlokovic BV (2013) An activated protein C analog stimulates neuronal production by human neural progenitor cells via a PAR1-PAR3-S1PR1-Akt pathway. J Neurosci 33:6181-6190. CrossRef Medline

Hack I, Bancila M, Loulier K, Carroll P, Cremer H (2002) Reelin is a detachment signal in tangential chain-migration during postnatal neurogenesis. Nat Neurosci 5:939-945. CrossRef Medline

Halin C, Scimone ML, Bonasio R, Gauguet JM, Mempel TR, Quackenbush E, Proia RL, Mandala S, von Andrian UH (2005) The S1P-analog FTY720 
differentially modulates T-cell homing via HEV: T-cell-expressed S1P1 amplifies integrin activation in peripheral lymph nodes but not in Peyer patches. Blood 106:1314-1322. CrossRef Medline

Harada J, Foley M, Moskowitz MA, Waeber C (2004) Sphingosine-1phosphate induces proliferation and morphological changes of neural progenitor cells. J Neurochem 88:1026-1039. CrossRef Medline

Hinds JW (1968) Autoradiographic study of histogenesis in the mouse olfactory bulb. I. Time of origin of neurons and neuroglia. J Comp Neurol 134:287-304. CrossRef Medline

Hisano Y, Kobayashi N, Yamaguchi A, Nishi T (2012) Mouse SPNS2 functions as a sphingosine-1-phosphate transporter in vascular endothelial cells. PLoS One 7:e38941. CrossRef Medline

$\mathrm{Hu} \mathrm{H}$ (2000) Polysialic acid regulates chain formation by migrating olfactory interneuron precursors. J Neurosci Res 61:480-492. CrossRef Medline

Hu H, Tomasiewicz H, Magnuson T, Rutishauser U (1996) The role of polysialic acid in migration of olfactory bulb interneuron precursors in the subventricular zone. Neuron 16:735-743. CrossRef Medline

Ihrie RA, Alvarez-Buylla A (2011) Lake-front property: a unique germinal niche by the lateral ventricles of the adult brain. Neuron 70:674-686. CrossRef Medline

Inta D, Alfonso J, von Engelhardt J, Kreuzberg MM, Meyer AH, van Hooft JA, Monyer H (2008) Neurogenesis and widespread forebrain migration of distinct GABAergic neurons from the postnatal subventricular zone. Proc Natl Acad Sci U S A 105:20994-20999. CrossRef Medline

Kim EJ, Ables JL, Dickel LK, Eisch AJ, Johnson JE (2011) Ascl1 (Mash1) defines cells with long-term neurogenic potential in subgranular and subventricular zones in adult mouse brain. PLoS One 6:e18472. CrossRef Medline

Kimura A, Ohmori T, Ohkawa R, Madoiwa S, Mimuro J, Murakami T, Kobayashi E, Hoshino Y, Yatomi Y, Sakata Y (2007) Essential roles of sphingosine 1-phosphate/S1P1 receptor axis in the migration of neural stem cells toward a site of spinal cord injury. Stem Cells 25:115-124. CrossRef Medline

Kunkel GT, Maceyka M, Milstien S, Spiegel S (2013) Targeting the sphingosine-1-phosphate axis in cancer, inflammation and beyond. Nat Rev Drug Discov 12:688-702. CrossRef Medline

Lalli G (2014) Extracellular signals controlling neuroblast migration in the postnatal brain. Adv Exp Med Biol 800:149-180. CrossRef Medline

Laplagne DA, Espósito MS, Piatti VC, Morgenstern NA, Zhao C, van Praag H, Gage FH, Schinder AF (2006) Functional convergence of neurons generated in the developing and adult hippocampus. PLoS Biol 4:e409. CrossRef Medline

Lazarini F, Lledo PM (2011) Is adult neurogenesis essential for olfaction? Trends Neurosci 34:20-30. CrossRef Medline

Lee MJ, Thangada S, Claffey KP, Ancellin N, Liu CH, Kluk M, Volpi M, Sha'afi RI, Hla T (1999) Vascular endothelial cell adherens junction assembly and morphogenesis induced by sphingosine-1-phosphate. Cell 99:301312. CrossRef Medline

Le Magueresse C, Alfonso J, Khodosevich K, Arroyo Martín AA, Bark C, Monyer H (2011) "Small axonless neurons": postnatally generated neocortical interneurons with delayed functional maturation. J Neurosci 31: 16731-16747. CrossRef Medline

Liu CH, Hla T (1997) The mouse gene for the inducible G-protein-coupled receptor edg-1. Genomics 43:15-24. CrossRef Medline

Liu Y, Wada R, Yamashita T, Mi Y, Deng CX, Hobson JP, Rosenfeldt HM, Nava VE, Chae SS, Lee MJ, Liu CH, Hla T, Spiegel S, Proia RL (2000) Edg-1, the G protein-coupled receptor for sphingosine-1-phosphate, is essential for vascular maturation. J Clin Invest 106:951-961. CrossRef Medline

Lois C, Alvarez-Buylla A (1994) Long-distance neuronal migration in the adult mammalian brain. Science 264:1145-1148. CrossRef Medline

Lois C, García-Verdugo JM, Alvarez-Buylla A (1996) Chain migration of neuronal precursors. Science 271:978-981. CrossRef Medline

Maceyka M, Harikumar KB, Milstien S, Spiegel S (2012) Sphingosine-1- phosphate signaling and its role in disease. Trends Cell Biol 22:50-60. CrossRef Medline

Matloubian M, Lo CG, Cinamon G, Lesneski MJ, Xu Y, Brinkmann V, Allende ML, Proia RL, Cyster JG (2004) Lymphocyte egress from thymus and peripheral lymphoid organs is dependent on S1P receptor 1. Nature 427:355-360. CrossRef Medline

McGiffert C, Contos JJ, Friedman B, Chun J (2002) Embryonic brain expression analysis of lysophospholipid receptor genes suggests roles for s1p(1) in neurogenesis and $\operatorname{sip}(1-3)$ in angiogenesis. FEBS Lett 531: 103-108. CrossRef Medline

Mitra P, Oskeritzian CA, Payne SG, Beaven MA, Milstien S, Spiegel S (2006) Role of ABCC1 in export of sphingosine-1-phosphate from mast cells. Proc Natl Acad Sci U S A 103:16394-16399. CrossRef Medline

Mizugishi K, Yamashita T, Olivera A, Miller GF, Spiegel S, Proia RL (2005) Essential role for sphingosine kinases in neural and vascular development. Mol Cell Biol 25:11113-11121. CrossRef Medline

Nam SC, Kim Y, Dryanovski D, Walker A, Goings G, Woolfrey K, Kang SS, Chu C, Chenn A, Erdelyi F, Szabo G, Hockberger P, Szele FG (2007) Dynamic features of postnatal subventricular zone cell motility: a twophoton time-lapse study. J Comp Neurol 505:190-208. CrossRef Medline

Ng KL, Li JD, Cheng MY, Leslie FM, Lee AG, Zhou QY (2005) Dependence of olfactory bulb neurogenesis on prokineticin 2 signaling. Science 308: 1923-1927. CrossRef Medline

Ono K, Tomasiewicz H, Magnuson T, Rutishauser U (1994) N-CAM mutation inhibits tangential neuronal migration and is phenocopied by enzymatic removal of polysialic acid. Neuron 13:595-609. CrossRef Medline

O'Sullivan C, Dev KK (2013) The structure and function of the S1P1 receptor. Trends Pharmacol Sci 34:401-412. CrossRef Medline

Paik JH, Skoura A, Chae SS, Cowan AE, Han DK, Proia RL, Hla T (2004) Sphingosine 1-phosphate receptor regulation of N-cadherin mediates vascular stabilization. Genes Dev 18:2392-2403. CrossRef Medline

Rao TS, Lariosa-Willingham KD, Lin FF, Palfreyman EL, Yu N, Chun J, Webb M (2003) Pharmacological characterization of lysophospholipid receptor signal transduction pathways in rat cerebrocortical astrocytes. Brain Res 990:182-194. CrossRef Medline

Saghatelyan A, de Chevigny A, Schachner M, Lledo PM (2004) Tenascin-R mediates activity-dependent recruitment of neuroblasts in the adult mouse forebrain. Nat Neurosci 7:347-356. CrossRef Medline

Saha B, Ypsilanti AR, Boutin C, Cremer H, Chédotal A (2012) Plexin-B2 regulates the proliferation and migration of neuroblasts in the postnatal and adult subventricular zone. J Neurosci 32:16892-16905. CrossRef Medline

Sato K, Malchinkhuu E, Horiuchi Y, Mogi C, Tomura H, Tosaka M, Yoshimoto Y, Kuwabara A, Okajima F (2007) Critical role of ABCAl transporter in sphingosine 1-phosphate release from astrocytes. J Neurochem 103:2610-2619. Medline

Snapyan M, Lemasson M, Brill MS, Blais M, Massouh M, Ninkovic J, Gravel C, Berthod F, Götz M, Barker PA, Parent A, Saghatelyan A (2009) Vasculature guides migrating neuronal precursors in the adult mammalian forebrain via brain-derived neurotrophic factor signaling. J Neurosci 29: 4172-4188. CrossRef Medline

Whitman MC, Fan W, Rela L, Rodriguez-Gil DJ, Greer CA (2009) Blood vessels form a migratory scaffold in the rostral migratory stream. J Comp Neurol 516:94-104. CrossRef Medline

Wichterle H, Garcia-Verdugo JM, Alvarez-Buylla A (1997) Direct evidence for homotypic, glia-independent neuronal migration. Neuron 18: 779-791. CrossRef Medline

Wittko IM, Schänzer A, Kuzmichev A, Schneider FT, Shibuya M, Raab S, Plate KH (2009) VEGFR-1 regulates adult olfactory bulb neurogenesis and migration of neural progenitors in the rostral migratory stream in vivo. J Neurosci 29:8704-8714. CrossRef Medline

Yu N, Lariosa-Willingham KD, Lin FF, Webb M, Rao TS (2004) Characterization of lysophosphatidic acid and sphingosine-1-phosphate-mediated signal transduction in rat cortical oligodendrocytes. Glia 45:17-27. CrossRef Medline 